\title{
Article \\ Epigenetic Modulation of SPCA2 Reverses Epithelial to Mesenchymal Transition in Breast Cancer Cells
}

\author{
Monish Ram Makena (D), Myungjun Ko, Donna Kimberly Dang and Rajini Rao*(D) \\ Department of Physiology, Johns Hopkins University School of Medicine, 725 N. Wolfe St, Baltimore, \\ MD 21205, USA; mmakena1@jhmi.edu (M.R.M.); myungjunko@mednet.ucla.edu (M.K.); \\ donna.dang@ucsf.edu (D.K.D.) \\ * Correspondence: rrao@jhmi.edu
}

Citation: Makena, M.R.; Ko, M.; Dang, D.K.; Rao, R. Epigenetic Modulation of SPCA2 Reverses Epithelial to Mesenchymal Transition in Breast Cancer Cells. Cancers 2021, 13, 259. https://doi.org/10.3390/ cancers13020259

Received: 12 November 2020 Accepted: 8 January 2021 Published: 12 January 2021

Publisher's Note: MDPI stays neutral with regard to jurisdictional clai$\mathrm{ms}$ in published maps and institutional affiliations.

Copyright: (C) 2021 by the authors. Licensee MDPI, Basel, Switzerland. This article is an open access article distributed under the terms and conditions of the Creative Commons Attribution (CC BY) license (https:// creativecommons.org/licenses/by/ $4.0 /)$.

Simple Summary: The triple receptor negative breast cancer subtype, or TNBC, currently has no tailored treatment options. TNBC is highly metastatic, associated with high patient mortality, and disproportionately occurs in Black/African American women where it contributes to racial disparities in health outcomes. Therefore, we focused on new therapeutic approaches to TNBC. We discovered that levels of the Calcium-ATPase SPCA2 are abnormally low in TNBC and that these low levels correlate with poor survival prognosis in patients. Previously, we showed that recombinant SPCA2 prevented TNBC cells from acquiring aggressive "mesenchymal" properties associated with metastasis both in vitro and in vivo. These findings motivated us to search for drugs that turn the SPCA2 gene back on in TNBC cells. In this study, we show that histone deacetylase inhibitors increase SPCA2 levels, activate $\mathrm{Ca}^{2+}$ signaling and convert cancer cells to a less aggressive "epithelial" state. These findings could lead to new treatment options for TNBC.

Abstract: The secretory pathway $\mathrm{Ca}^{2+}$-ATPase SPCA2 is a tumor suppressor in triple receptor negative breast cancer (TNBC), a highly aggressive molecular subtype that lacks tailored treatment options. Low expression of SPCA2 in TNBC confers poor survival prognosis in patients. Previous work has established that re-introducing SPCA2 to TNBC cells restores basal $\mathrm{Ca}^{2+}$ signaling, represses mesenchymal gene expression, mitigates tumor migration in vitro and metastasis in vivo. In this study, we examined the effect of histone deacetylase inhibitors (HDACi) in TNBC cell lines. We show that the pan-HDACi vorinostat and the class I HDACi romidepsin induce dose-dependent upregulation of SPCA2 transcript with concurrent downregulation of mesenchymal markers and tumor cell migration characteristic of epithelial phenotype. Silencing SPCA2 abolished the ability of HDACi to reverse epithelial to mesenchymal transition (EMT). Independent of ATPase activity, SPCA2 elevated resting $\mathrm{Ca}^{2+}$ levels to activate downstream components of non-canonical Wnt/Ca ${ }^{2+}$ signaling. HDACi treatment led to SPCA2-dependent phosphorylation of CAMKII and $\beta$-catenin, turning Wnt signaling off. We conclude that SPCA2 mediates the efficacy of HDACi in reversing EMT in TNBC by a novel mode of non-canonical Wnt $/ \mathrm{Ca}^{2+}$ signaling. Our findings provide incentive for screening epigenetic modulators that exploit $\mathrm{Ca}^{2+}$ signaling pathways to reverse EMT in breast tumors.

Keywords: TNBC; $\mathrm{Ca}^{2+}$-ATPase; SICE; HDAC inhibitors; EMT; WNT signaling; vorinostat; romidepsin; vimentin

\section{Introduction}

Triple receptor negative breast cancer (TNBC) is a molecular subtype characterized by the lack of estrogen receptor (ER), progesterone receptor (PR), and receptor for human epidermal growth factor-2 (HER2), making it unsuitable for endocrine or targeted antibody therapy [1]. Although TNBC constitutes an estimated 12-15\% of all breast cancer subtypes, it is 2.2 times more prevalent in Black/African American women, compared 
to White/European American women, contributing significantly to the racial disparity in breast cancer outcomes [2]. TNBC tumors are characterized by early relapse and high rates of visceral metastasis [3]. Thus, the lack of tailored treatment options for TNBC, its highly aggressive nature and prevalence in women of color demands urgent focus on new therapeutic approaches.

We recently established a novel role for the secretory pathway $\mathrm{Ca}^{2+}$-ATPase SPCA2 as a tumor suppressor in TNBC. Loss of SPCA2 and basal $\mathrm{Ca}^{2+}$ signaling in TNBC cells was found to promote epithelial-mesenchymal transition, a hallmark of metastasis, during which cancer cells lose their polarity and cell-cell contacts, thereby acquiring the ability to migrate [4]. At the molecular level, the process of EMT coincides with the loss of epithelial markers, notably the $\mathrm{Ca}^{2+}$ binding cell adhesion protein E-cadherin. Conversely, EMT is characterized by gain in expression of mesenchymal genes, including $\mathrm{N}$-cadherin and zinc-finger transcription factors such as Snail, Slug, and Zeb1 that reprogram the cancer cell to acquire malignant invasive phenotypes [5]. These gene expression changes serve as convenient markers to track reversible EMT changes in breast cancer cells.

In proof-of-principle experiments we showed that ectopic expression of SPCA2 in TNBC cell lines enhanced post-translational stability of E-cadherin, repressed mesenchymal gene expression and tumor cell migration in vitro and mitigated tumor metastasis in vivo [4]. Increased surface expression of E-cadherin by SPCA2 activated the tumor suppressor Hippo signaling pathway, resulting in nuclear exclusion and degradation of the transcriptional co-activator YAP (Yes-activated protein) and contact-mediated growth inhibition [4].

Having validated SPCA2 as a potential molecular target in TNBC, our next step is to explore effective treatment options. In this study, we evaluate the efficacy of epigenetic modulators to increase SPCA2 expression in TNBC cell lines. Histone acetyltransferases (HATs) and histone deacetylases (HDACs) counteract each other to regulate gene expression by altering chromatin structure. HDACs remove acetyl groups from lysine residues on histone proteins to condense chromatin and repress gene transcription [6]. Thus, histone deacetylase inhibitors (HDACi) can restore expression of tumor suppressor or endocrine target genes, and a few are being evaluated singly or in combination in clinical trials for the treatment of TNBC/metastatic cancers [7,8]. To date, four HDACi (vorinostat, romidepsin, panobinostat, and belinostat) have been approved as second line treatment for relapsed peripheral T-cell lymphoma (PTCL) and/or cutaneous T-cell lymphoma (CTCL) and multiple myeloma by the FDA [6,9]. Alteration in calcium signaling resulted in reactivation of tumor suppressor genes in cancer cells [10]. Some HDACi reportedly regulate intracellular $\mathrm{Ca}^{2+}$ levels [11]. At clinically relevant drug concentrations, HDACi have been reported to elevate expression of E-cadherin, while suppressing several mesenchymal genes, thereby decreasing migration in vitro and metastasis in vivo in triple negative breast cancer cell lines [12-16]. These observations strongly suggest that HDAC inhibitors may upregulate transcription of SPCA2 in TNBC to mediate downstream effects on EMT and metastasis. In this study, we investigated the ability of specific HDAC inhibitors to restore SPCA2 expression and correct dysregulated $\mathrm{Ca}^{2+}$ signaling in TNBC.

SPCA2 has dual roles: first, in delivery of $\mathrm{Ca}^{2+}$ to the lumen of the Golgi and secretory vesicles where it is important for protein sorting, processing, and trafficking; and second, in activating $\mathrm{Ca}^{2+}$ entry through Orai1 ion channels for downstream signaling events. ATP hydrolysis is required for $\mathrm{Ca}^{2+}$ transport into the Golgi and secretory pathway but not for Orai1 mediated $\mathrm{Ca}^{2+}$ entry $[17,18]$. In this study we distinguish between these dual $\mathrm{Ca}^{2+}$ pumping and signaling roles of SPCA2 in mediating mesenchymal to epithelial transition (MET) of TNBC cells. Importantly, we uncover a novel role for SPCA2 in activating downstream components of $\mathrm{Wnt} / \mathrm{Ca}^{2+}$ signaling pathway. The Wingless-type (Wnt) signaling pathway is an ancient and evolutionarily conserved pathway that regulates embryonic development and drives malignant transformation of cancer cells, leading to EMT, metastasis, and cancer stem cell maintenance [19]. Frequent epigenetic inactivation of Wnt antagonist genes were reported in breast cancer [20]. In the non-canonical Wnt/ $\mathrm{Ca}^{2+}$ 
pathway, elevated $\mathrm{Ca}^{2+}$ levels activate calcium-binding proteins, including protein kinase $\mathrm{C}$ (PKC), calcineurin, and calmodulin-dependent kinase II (CamKII). CaMKII was reported to phosphorylation $\beta$-catenin at T332, T472, and S552 $[19,21]$. Once the $\beta$-Catenin is phosphorylated, ubiquitin E3 ligase $\beta$-TrCP recognizes phosphorylated $\beta$-catenin and promotes its ubiquitination and proteasome degradation, which then promotes MET [22-24]. In this study we demonstrate that upregulation of SPCA2 by HDACi activates downstream components of the Wnt $/ \mathrm{Ca}^{2+}$ pathway in TNBC cells, which is both necessary and sufficient to mediate key molecular events in MET.

\section{Results}

2.1. Low Expression of SPCA2 in TNBC Correlates with Poor Survival Prognosis

SPCA2 transcript levels are low in triple receptor negative breast cancer derived cell lines [4]. Here, we analyze the TCGA database to show that transcript levels of SPCA2 are significantly $(p<0.0001)$ lower in receptor negative breast tumors compared to receptor positive tumors (Figure 1A). In contrast, levels of the closely related housekeeping isoform SPCA1 were significantly higher in receptor negative tumors (Figure 1B). In TNBC, patients with low SPCA2 levels had poorer regression-free survival (Hazard ratio $=0.62(0.4-0.95)$; Logrank $p=0.027$; Figure 1C), whereas this trend is not observed for SPCA1 (Logrank $p=0.13$; Figure 1D). These observations suggest that SPCA2 could play a role as a tumor suppressor in TNBC.
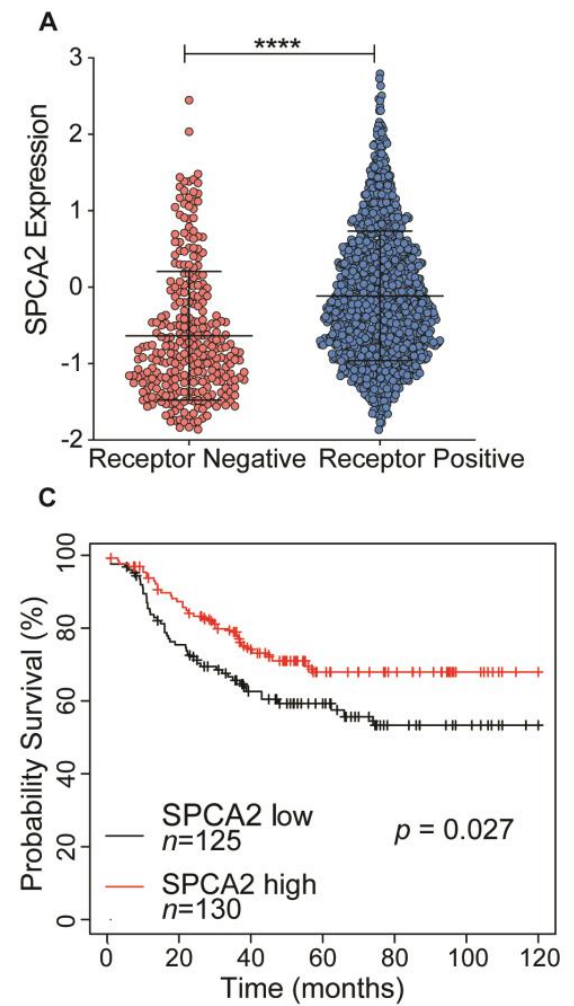
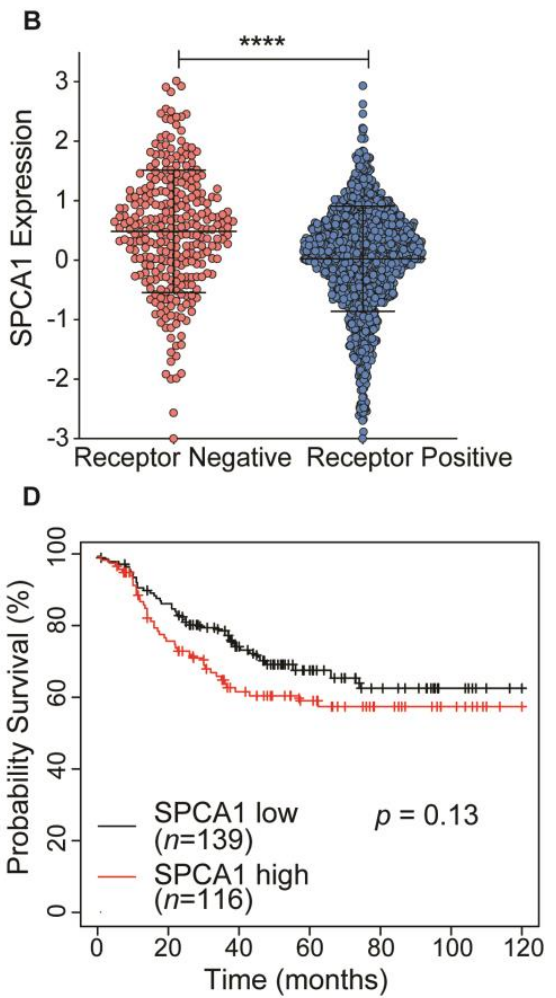

Figure 1. Isoform-specific expression and survival prognosis of SPCA genes in triple receptor negative breast cancer (TNBC). (A,B) Expression of (A) SPCA2 and (B) SPCA1 was analyzed in receptor positive and negative (TNBC) breast cancers from TCGA database; $n=290$ for receptor-negative patients and $n=1222$ for receptor-positive patients. (C,D) Kaplan-Meier analysis of regression-free survival in patients stratified by (C) SPCA2 or (D) SPCA1 expression level. Data from KMplotter selected ER, PR, and HER2 (negative). Hazard ratio $=0.62(0.4-0.95)$; Logrank test, $n=125$ in low SPCA2 group, and $n=130$ in high SPCA2 group. Hazard ratio= $1.38(0.91-2.11)$, Logrank test, $n=139$ in low SPCA1 group and $n=116$ in high SPCA1 group. ${ }^{* * *} p<0.0001$. 


\subsection{HDAC Inhibitors Increase SPCA2 Expression in TNBC Cells}

Previously, we showed that ectopic expression of recombinant SPCA2 (SPCA2R) in TNBC cell lines reduced tumor cell migration in vitro and tumor metastasis in vivo [4]. These findings prompted a search of pharmacological agents that could increase endogenous SPCA2 gene expression as potential therapeutic approach for TNBC. The addition of acetyl groups to lysine residues on histone proteins modifies chromatin structure and represses gene transcription. Thus, histone deacetylase inhibitors (HDACi) restore expression of tumor suppressor or endocrine target genes $[13,25,26]$ and are being evaluated singly or in combination in clinical trials for the treatment of TNBC/metastatic cancers $[8,27,28]$. Indeed, epigenetic modulators have been reported to regulate expression of other members of the $\mathrm{Ca}^{2+}$-ATPase family [11].

A comparison of histone modifications in the promoter region of the ATP2C2 gene encoding SPCA2 between normal human mammary epithelial cells (HMEC) and the breast cancer cell line MCF-7 revealed significant elevation of H3K27 histone acetylation in the tumor cells corresponding to high expression of SPCA2 in this cell line [29] (Figure S1A,B). Thus, we posited that HDACi could restore SPCA2 expression in TNBC (Figure 2A) and evaluated the effect of the pan-HDACi vorinostat and the class I HDACi romidepsin [30] on SPCA2 expression in the metastatic breast cancer cell lines, MDA-MB-231 and Hs578T.

A
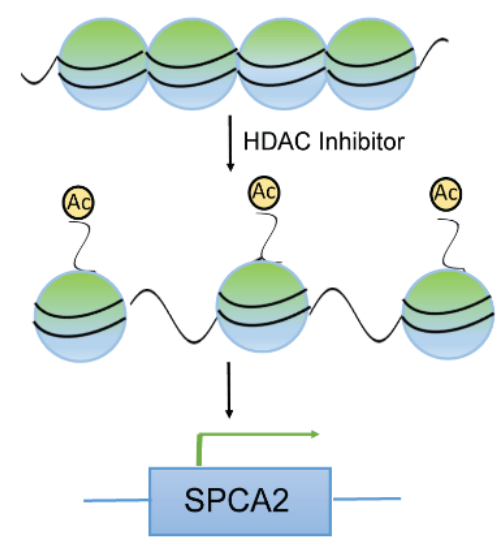

C

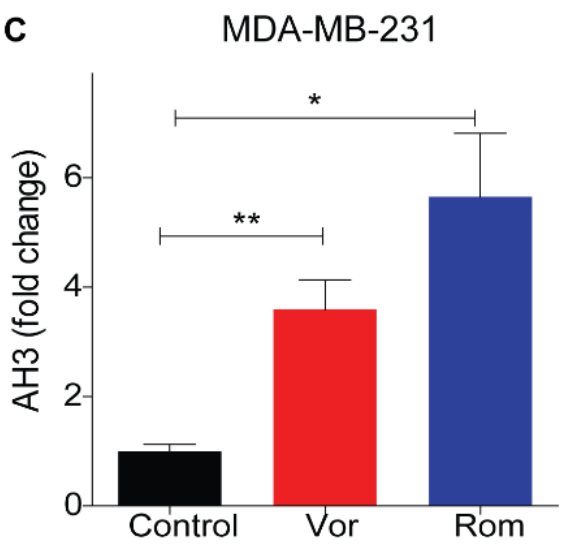

B

MDA-MB-231
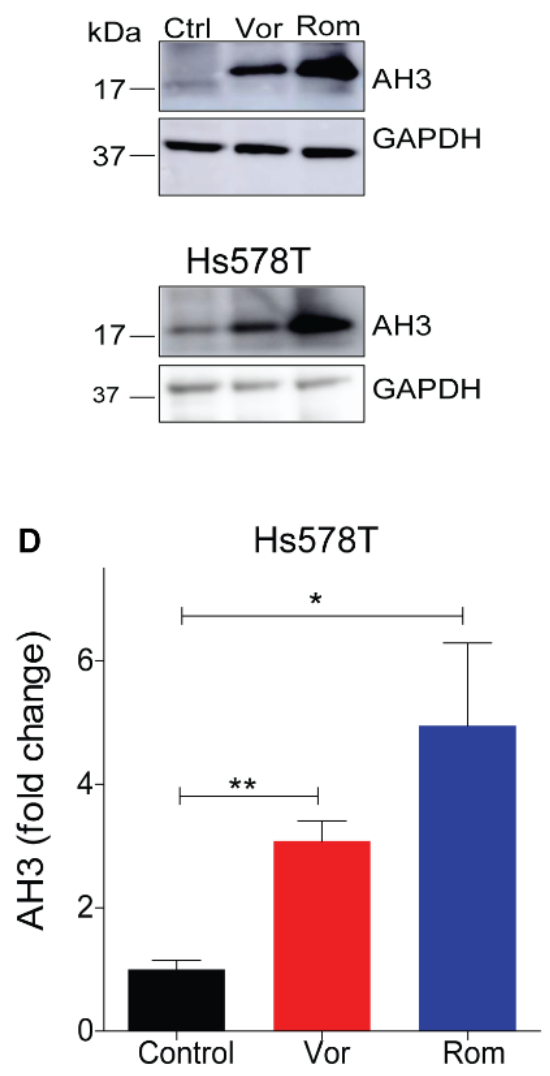

Figure 2. Cont. 

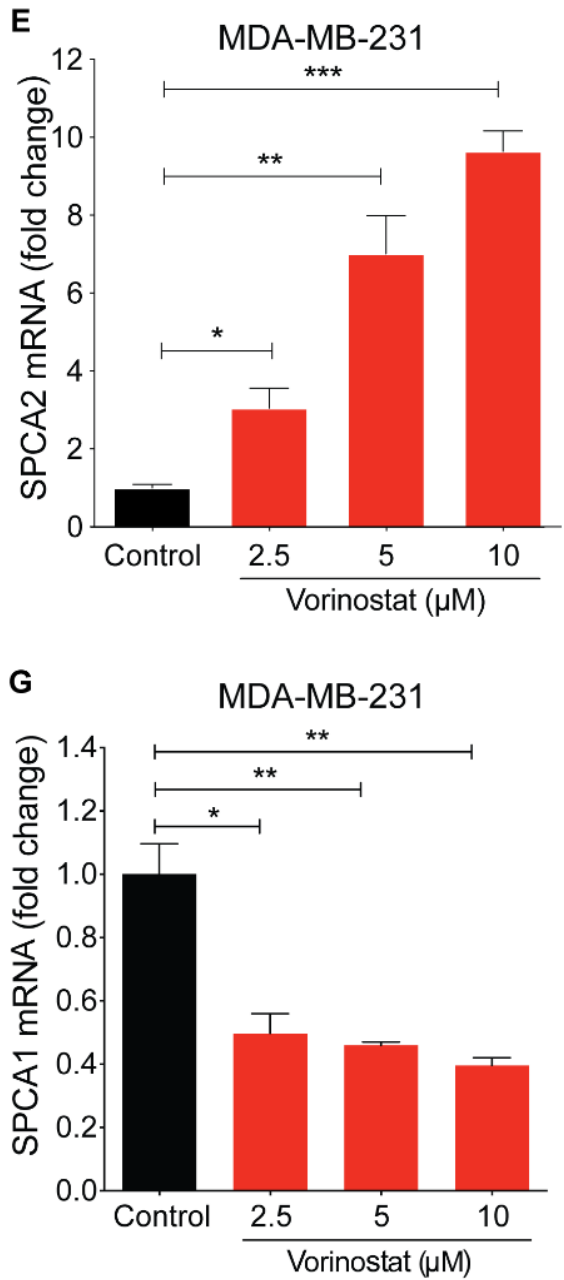
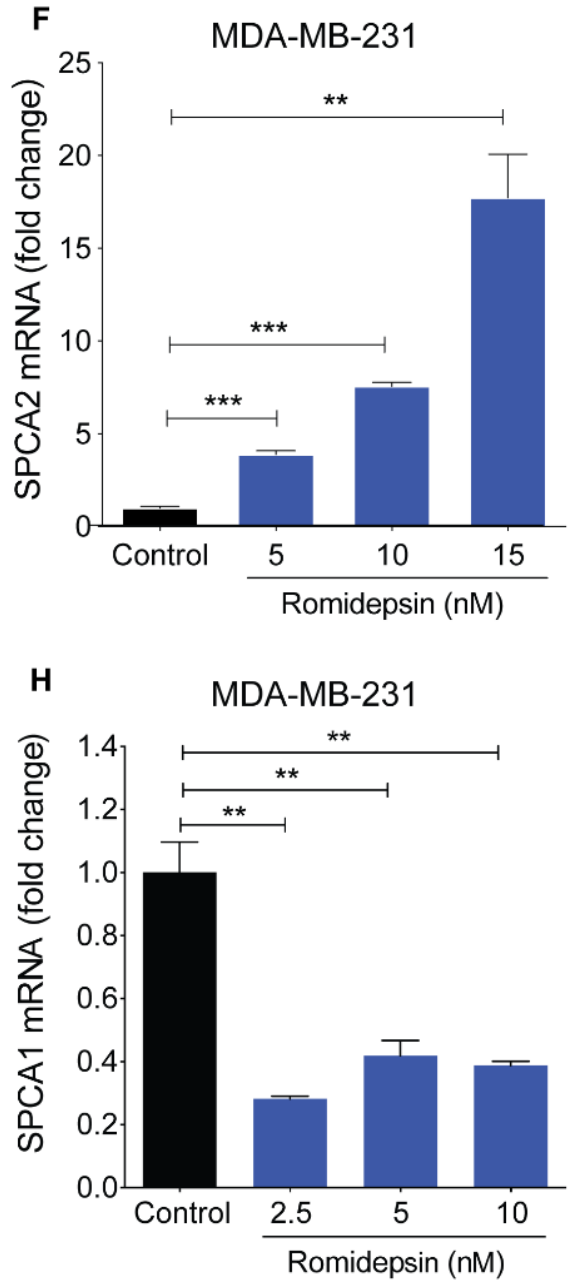

Figure 2. Epigenetic modulation of SPCA2 in TNBC. (A) Schematic showing hypothetical effect of histone deacetylase inhibitors (HDAC) inhibitors on SPCA2 expression. (B) Representative western blot of histone acetylation in MDA-MB-231 and HS578T cells after treatment with vorinostat $(2.5 \mu \mathrm{M})$ or romidepsin (5 $\mathrm{nM}$ ) for $24 \mathrm{~h}$. GAPDH was used as a loading control (C,D) Quantitation of Western blots $(n=3)$ by densitometry. (E,F) Treatment of MDA-MB-231 cells with HDAC inhibitors vorinostat $(2.5,5,10 \mu \mathrm{M})$ and romidepsin $(5,10,15 \mathrm{nM})$ for $24 \mathrm{~h}$ resulted in significant dose-dependence increase of the SPCA2 transcript, $n=3$. $(\mathbf{G}, \mathbf{H})$ Treatment of MDA-MB-231 cells with HDAC inhibitors vorinostat $(2.5,5,10 \mu \mathrm{M})$ and romidepsin $(5,10,15 \mathrm{nM})$ for $24 \mathrm{~h}$ resulted in significant decrease of the SPCA1 transcript, $n=3$. Student's $t$-test, ${ }^{* * *} p<0.001,{ }^{* *} p<0.01,{ }^{*} p<0.05$.

As expected, vorinostat and romidepsin significantly increased histone acetylation, a hallmark of HDAC inhibitor activity, in both TNBC cell lines (Figure 2B-D). We observed a significant dose-dependent up-regulation of SPCA2 transcript with vorinostat and romidepsin with $24 \mathrm{~h}$ exposure to clinically relevant drug concentrations in MDA-MB-231 (Figure 2E,F). SPCA2 transcript increased with longer treatments as seen for romidepsin (5 nM) over 24 and $48 \mathrm{~h}$ (Figure S1C). Similar transcriptional changes were observed in Hs578T where both vorinostat $(2.5 \mu \mathrm{M})$ and romidepsin $(5 \mathrm{nM})$ elicited approximately fivefold increase in SPCA2 expression (Figure S1D). We found that other classes of epigenetic modulators could enhance SPCA2 expression levels as well. The DNA demethylating agent 5-azacytidine $(10 \mu \mathrm{M})$ and the natural polyphenol resveratrol $(25 \mu \mathrm{M})$ which has broad epigenetic regulatory effects, elicited $\sim 3$-fold increase of SPCA2 in MDA-MB-231 cells (Figure S1E,F).

In contrast, SPCA1 levels were significantly down regulated by vorinostat and romidepsin in MDA-MB-231 cells (Figure 2G,H). These opposing transcriptional changes in 
SPCA1 and SPCA2 illustrate distinct, isoform specific effects of HDACi and are consistent with our previous finding that expression of SPCA1 and SPCA2 is clustered differentially with mesenchymal and epithelial signature gene markers, respectively $[4,18]$.

\subsection{HDAC Inhibitors Promote MET Transition in TNBC Cells}

Ectopic expression of SPCA2R was found to diminish mesenchymal gene expression in TNBC cells [4]. Therefore, we evaluated whether concentrations of vorinostat $(2.5 \mu \mathrm{M})$, shown to induce a modest threefold increase in SPCA2 expression (Figure 2E), would be sufficient to elicit MET (Figure 3A). Vimentin is a cytoskeletal intermediate filament protein that is frequently used as a mesenchymal marker. Here we show that treatment of TNBC cell lines with HDAC inhibitors significantly decreased vimentin mRNA (Figure 3B,C) and protein (Figure 3D-F) in MDA-MB-231 and Hs578T cell lines. Decreased cellular expression of vimentin in vorinostat treated MDA-MB-231 cells was confirmed by immunostaining and confocal microscopy (Figure 3G,H). Vimentin filament assembly in mesenchymal cells is associated with loss of cell contacts and increased motility, which are hallmarks of metastatic progression [31]. We show that treatment of MDA-MB-231 cells with vorinostat significantly decreased migration in Boyden chambers when compared to control (Figure 3I,J).

A

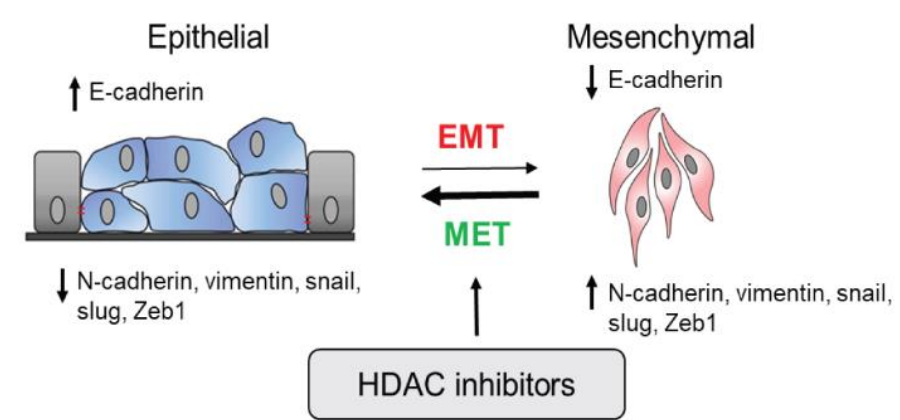

B

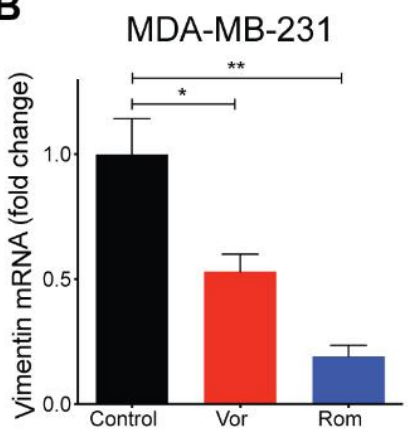

C Hs578T

D

MDA-MB-231

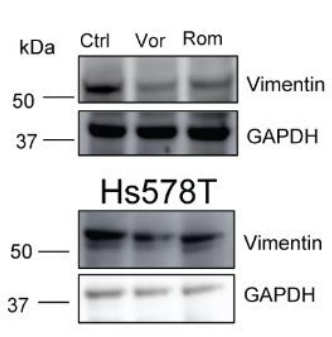

E

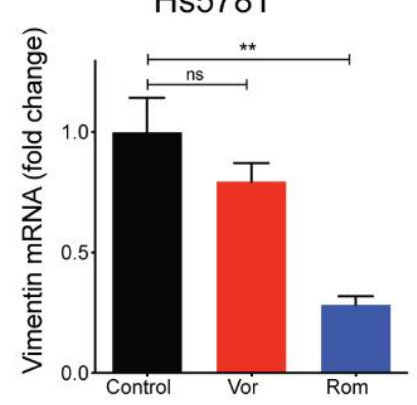

$\mathbf{F}$

Figure 3. Cont.
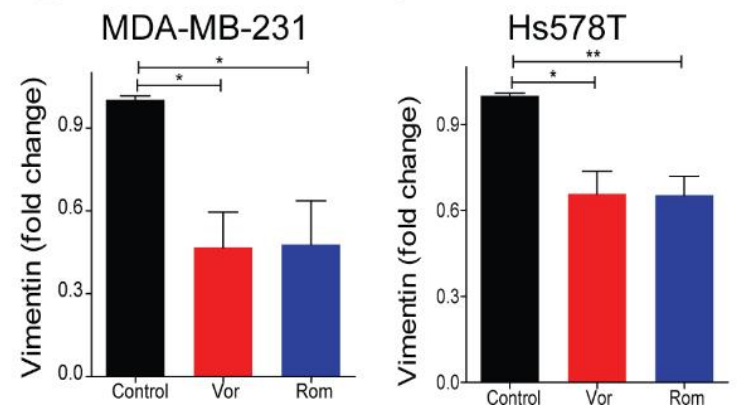
G

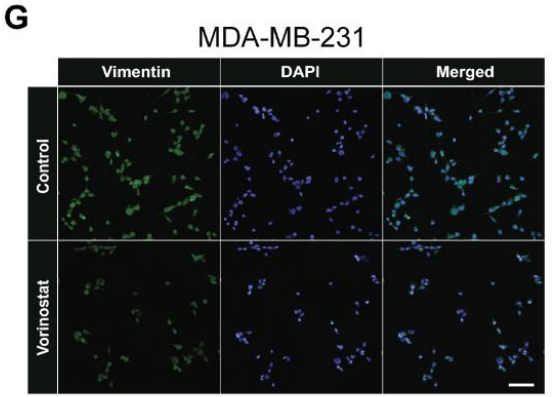

I

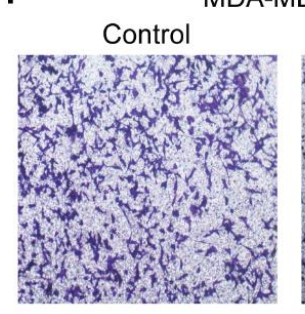

MDA-MB-231

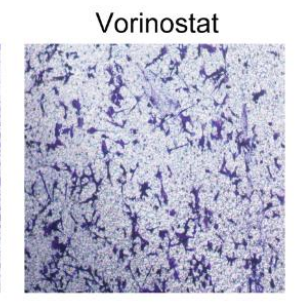

H

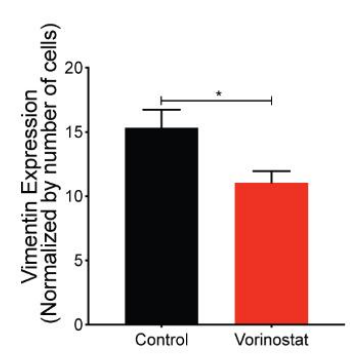

$\mathbf{J}$

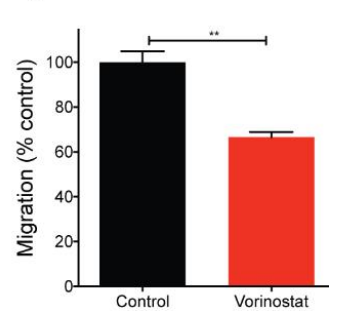

Figure 3. HDAC inhibitors promote mesenchymal to epithelial transition (MET) phenotype TNBC cells. (A) Schematic showing HDAC inhibitors promote MET. Epithelial and mesenchymal states are characterized by gene expression markers that increase or decrease, as indicated, upon transition between states. (B,C) Vimentin mRNA, determined by qPCR, decreased following treatment of MDA-MB-231 (B) and Hs578T (C) with vorinostat $(2.5 \mu \mathrm{M})$ and romidepsin $(5 \mathrm{nM})$ for $24 \mathrm{~h} . n=3$. (D) Vimentin protein expression (vorinostat $(2.5 \mu \mathrm{M})$ and romidepsin $(5 \mathrm{nM})$ for $24 \mathrm{~h}$ ) was detected using Western blotting in the indicated TNBC cell lines; GAPDH was used as a loading control. $(\mathrm{E}, \mathrm{F})$ Quantitation of Western blots $(n=3)$ by densitometry. (G) Representative confocal microscope images showing immunofluorescence staining of vimentin in MDA-MB-231 cells treated with vehicle (control) or vorinostat $(2.5 \mu \mathrm{M})$ for $24 \mathrm{~h}$. ( $40 \times$ magnification; scale bar, $50 \mu \mathrm{m})$. (H) Vimentin staining was quantified by ImageJ software (National Institute of Health, Bethesda, MD, USA), and divided by number $(n)$ of cells, $n=352$ in control, $n=141$ for vorinostat. (I) Representative microscope images of MDA-MB-231 cells treated with vehicle or vorinostat $(2.5 \mu \mathrm{M})$ for $24 \mathrm{~h}$, in Boyden chamber $(10 \times$ magnification). (J) Migration was quantified by ImageJ software from 3 images for each condition. Significance was determined by Student $t$-test, ${ }^{* *} p<0.01,{ }^{*} p<0.05,{ }^{\text {ns }} p>0.05$.

In addition, HDAC inhibitors suppressed expression of several signature mesenchymal genes, including CDH2 (N-cadherin), SNAI2 (Snail2), and ZEB1 (Zinc Finger E-Box Binding Homeobox 1) in TNBC cell lines (Figure S2A-F). Reciprocally, HDAC inhibitors elevated expression of the epithelial marker E-cadherin (CDH1) in MDA-MB-231, although not in HS578T (Figure S2G,H), where endogenous CDH1 expression is already sevenfold higher compared to MDA-MB-231 (Figure S2I). While these results are consistent with previous findings on HDACi effects [15,16,32], they suggest the intriguing possibility that key therapeutic features associated with HDACi in TNBC cells (Figure 3A) may be mediated by epigenetic modulation of SPCA2.

\subsection{SPCA2 Is Required for HDACi-Induced MET Changes in TNBC Cell Lines}

Histone deacetylase inhibitors have pleiotropic cellular effects on a wide range of transcriptional and non-transcriptional targets, resulting in alteration of apoptosis, differentiation, signaling, and many other pathways central to cancer cell fate and function [33]. We hypothesized that SPCA2 is an upstream target of HDACi that could mediate further downstream effects characteristic of MET (Figure 4A). To test this hypothesis, we used lentiviral expression of silencing constructs to further reduce the already low levels of SPCA2 transcript in MDA-MB-231 cells [4] (Figure 4B). SPCA2 knockdown (SPCA2 KD) resulted in the increased expression of mesenchymal genes, including N-cadherin, SNAI1, 
and vimentin (Figure S3). Similar results were observed earlier in MCF-7 cell line [4]. As expected, vorinostat failed to increase SPCA2 levels in SPCA2 KD cells (Figure 4C).
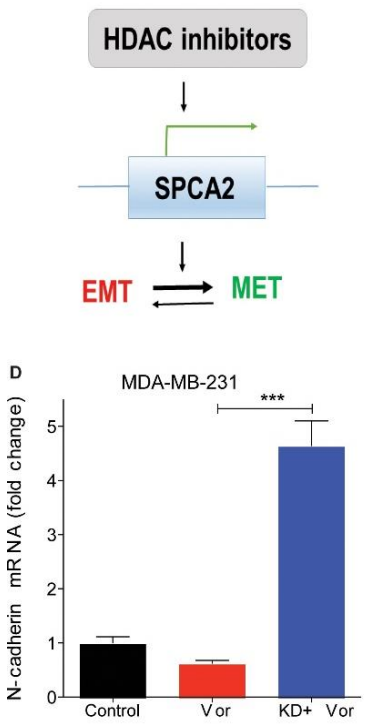

G

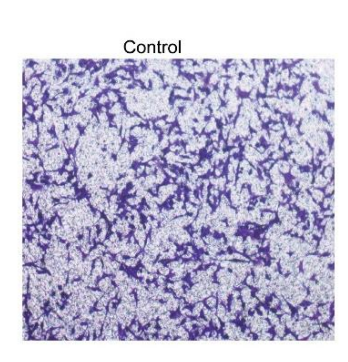

B

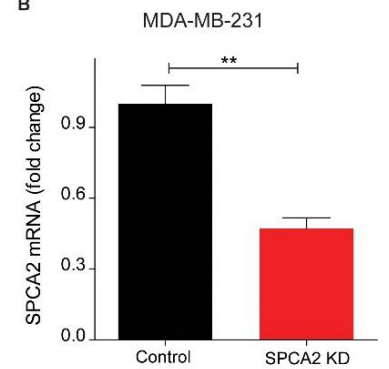

E

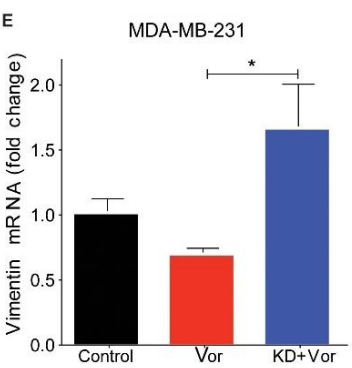

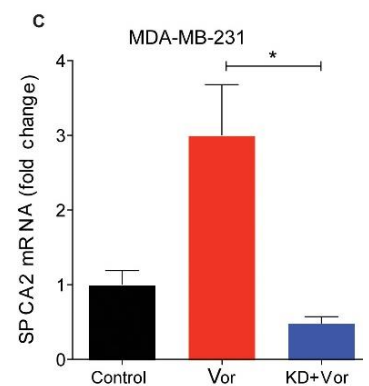

F MDA-MB-231

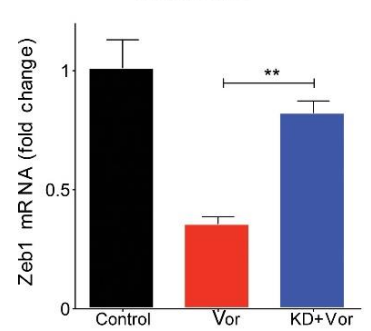

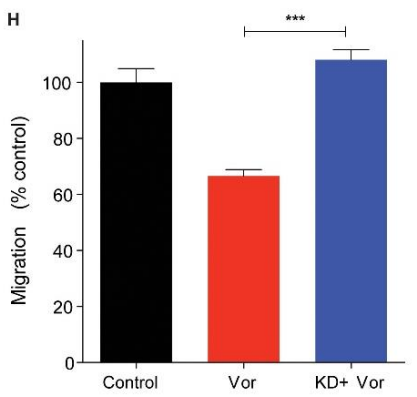

MDA-MB-231

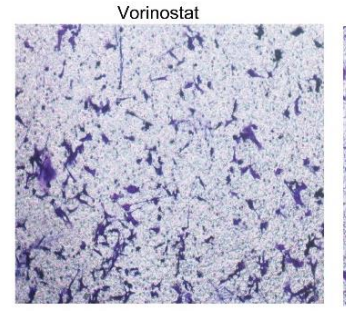

$\mathrm{KD}+$ Vorinostat

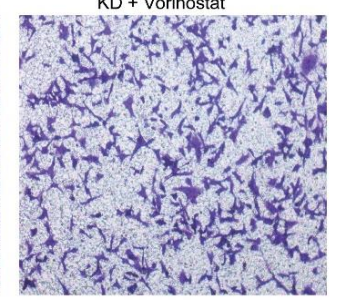

I

MDA-MB-231

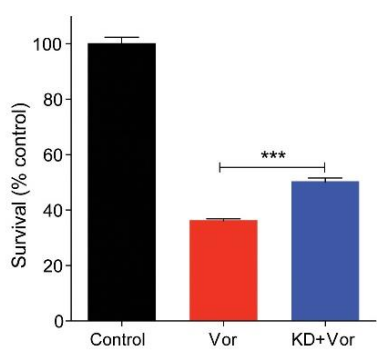

Figure 4. SPCA2 is required for HDACi-induced MET changes in TNBC cell lines. (A) Schematic showing that HDAC inhibitors regulate SPCA2 expression, which in turn, promotes MET. (B) SPCA2 mRNA, determined by qPCR, shows efficacy of knockdown (KD) in MDA-MB-231 cells relative to scramble shRNA control, and (C) following treatment with vehicle (control) or vorinostat $(2.5 \mu \mathrm{M})$ for $24 \mathrm{~h}$, as indicated. (D-F) Expression of mesenchymal gene markers N-cadherin, vimentin and ZEB1 was determined by qPCR following treatment with vehicle (control) or vorinostat $(2.5 \mu \mathrm{M})$. SPCA2KD effectively reversed decrease in mesenchymal gene expression in the presence of vorinostat. $n=3$. (G) Representative microscope images of MDA-MB-231 cells and MDA-MB-231 SPCA2 KD treated with vehicle or vorinostat $(2.5 \mu \mathrm{M})$ for $24 \mathrm{~h}$, in Boyden chamber $(10 \times$ magnification). (H) Migration was quantified by ImageJ software from 3 images for each condition. (I) SPCA2 KD in MDA-MB-231 significantly reduced cytotoxic effect of vorinostat $(n=6,2.5 \mu \mathrm{M}$ for $80 \mathrm{~h}$, MTT assay). Student $t$-test, ${ }^{* * *} p<0.001, * * p<0.01,{ }^{*} p<0.05$.

Importantly, we show that silencing of SPCA2 prevented downregulation of mesenchymal markers vimentin, N-cadherin, and ZEB1 by vorinostat; instead, transcripts 
of these mesenchymal markers were increased above untreated control (Figure 4D-F). These reversals were also seen in cellular phenotypes: we show that vorinostat-mediated inhibition of migration was effectively abolished by SPCA2 knockdown (Figure 4G,H). Further, vorinostat cytotoxicity was significantly abrogated by SPCA2 knockdown (Figure $4 \mathrm{I}$ ). These results support our hypothesis (Figure 4A) of a prominent and novel cellular role for SPCA2 in the efficacy of HDACi in mediating mesenchymal to epithelial transition in TNBC.

\subsection{Induction of MET by SPCA2 Is Independent of $\mathrm{Ca}^{2+}$ Pumping Activity}

Similar to other P-type ATPases, the ion pumping activity of SPCA2 requires ATP hydrolysis for the delivery of $\mathrm{Ca}^{2+}$ ions into the lumen of the secretory pathway for protein sorting and trafficking [29]. Therefore, we asked if the $\mathrm{Ca}^{2+}$-ATPase activity of SPCA2 was required for eliciting MET. A conserved aspartate is essential for formation of the catalytic phosphoenzyme intermediate in all P-type ATPases, including SPCA2. Previously, we showed that mutation of this aspartate in SPCA2 (D379N) inactivated $\mathrm{Ca}^{2+}$ pumping activity without affecting protein expression and Golgi localization $[29,34]$. Here we show that ectopic expression of SPCA2 mutant D379N [34], suppresses mesenchymal gene markers, including vimentin (Figure 5A,B), N-cadherin, SNAI1 and SNAI2, and ZEB1 (Figure 5C-F), similar to wild type SPCA2R, reported previously [4].

Unlike other P-type ATPases, SPCA2 has a unique function in mediating store independent $\mathrm{Ca}^{2+}$ entry (SICE) $[29,35]$, so called because it is distinct from store operated $\mathrm{Ca}^{2+}$ entry (SOCE) that occurs upon depletion of endoplasmic reticulum $\mathrm{Ca}^{2+}$ stores. Independent of ATPase activity, SPCA2 chaperones and activates the Orai1 $\mathrm{Ca}^{2+}$ channel to elevate resting $\mathrm{Ca}^{2+}$ levels in the cytoplasm [29]. We ectopically expressed recombinant SPCA2 (SPCA2R) or the catalytically inactive D379N mutant in MDA-MB-231 cells and imaged live cells using the ratiometric $\mathrm{Ca}^{2+}$ indicator Fura-2 (Figure 5G,I). As seen by the emission ratio from 340 and $380 \mathrm{~nm}$ excitation (Figure 5H,J), D379N elicited the elevation of resting cytoplasmic $\mathrm{Ca}^{2+}$ similar to SPCA2R control. These findings suggest that SPCA2 mediates MET through an elevation of cytoplasmic $\mathrm{Ca}^{2+}$.

\subsection{SPCA2 Activates the Wnt/Ca ${ }^{2+}$ Signaling Pathway in TNBC Cells}

Wnt signaling is a well-known regulator of cell fate, including self-renewal, proliferation, differentiation, and apoptosis, both in normal mammary development and in breast cancer [36]. The key effector protein in canonical Wnt signaling is $\beta$-catenin. When the Wnt pathway is OFF, $\beta$-catenin is phosphorylated and degraded. When Wnt is ON, $\beta$-catenin can translocate to the nucleus to activate genes that promote self-renewal and stemness associated with the mesenchymal state. In the non-canonical $\mathrm{Wnt} / \mathrm{Ca}^{2+}$ pathway, a rise in cytosolic $\mathrm{Ca}^{2+}$ has an antagonistic effect on canonical Wnt signaling. Wnt-mediated release of $\mathrm{Ca}^{2+}$ from endoplasmic reticulum stores phosphorylates $\mathrm{Ca}^{2+}$-calmodulin activated kinase, CAM Kinase II, leading to phosphorylation and degradation of $\beta$-catenin, turning Wnt signaling OFF [37]. We hypothesized that elevation of basal $\mathrm{Ca}^{2+}$ by SPCA2 could directly activate downstream components of $\mathrm{Wnt} / \mathrm{Ca}^{2+}$ signaling to mediate MET (Figure 6A). Ectopic expression of SPCA2R in MDA-MB-231 increased phosphorylation of CAM Kinase II, by 2 -fold, and increased phosphorylation of $\beta$-catenin by 2.5 -fold (Figure 6B-D). Consistent with these findings, addition of $2 \mathrm{mM}$ extracellular $\mathrm{Ca}^{2+}$ to cells maintained in nominally $\mathrm{Ca}^{2+}$-free culture medium increased phospho-CAMK II and decreased non-phospho (active) $\beta$-catenin and total $\beta$-catenin levels revealing a novel role for extracellular $\mathrm{Ca}^{2+}$ in Wnt/ $\mathrm{Ca}^{2+}$ signaling (Figure S4). To determine if SPCA2R-mediated CAMK II signaling was important for MET related gene expression changes, we treated cells with the CAMK II inhibitor (CKI, KN-93). We found that transcriptional downregulation of N-cadherin, vimentin and ZEB1 by SPCA2R expression in MDA-MB-231 cells was reversed by CKI treatment (Figure 6E-G). 
A
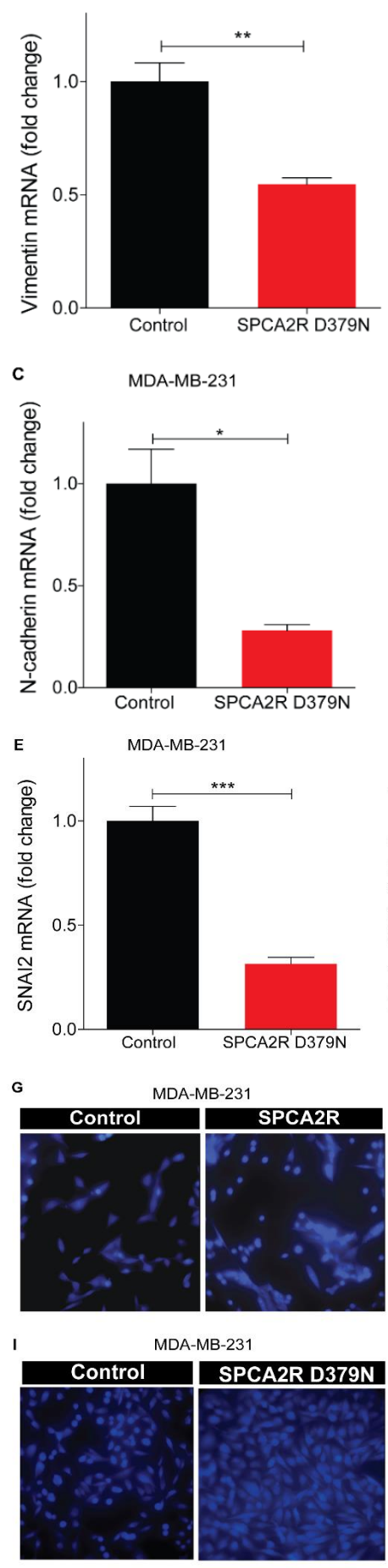

B MDA-MB-231

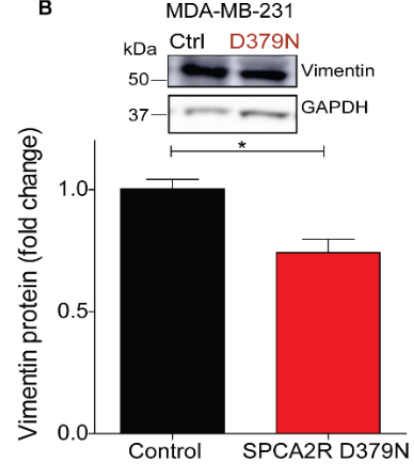

D MDA-MB-231

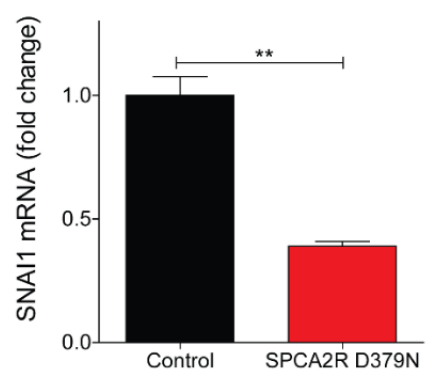

MDA-MB-231
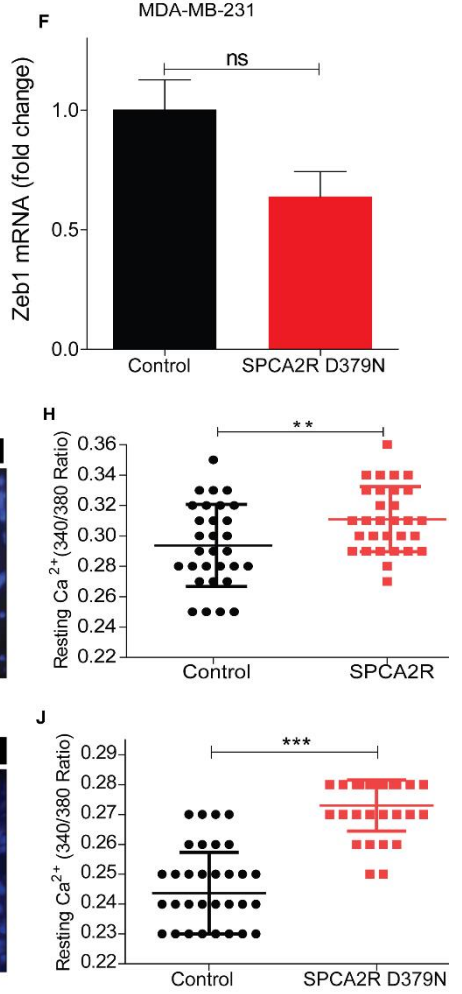

Figure 5. Induction of MET by SPCA2 is independent of $\mathrm{Ca}^{2+}$-ATPase activity. (A,B) Ectopic expression of SPCA2 mutant D379N in MDA-MB-231 significantly decreased vimentin compared to control, as determined by (A) qPCR $(n=3)$ or (B) Western blotting. GAPDH was used as a loading control. Quantified by densitometry $(n=3)$. (C-F) Mesenchymal gene markers, measured by qPCR, were decreased following ectopic expression of SPCA2R D379N as shown. $n=3$. (G-J) Representative live cell Ca ${ }^{2+}$ imaging baseline readings $\left(10 \times\right.$ magnification) in $\mathrm{Ca}^{2+}$-free conditions using Fura2-AM treated MDA-MB-231 cells with or without SPCA2R (G) or D379N (I). Fluorescence emission ratio of 340/380 nm showing increase in average resting $\mathrm{Ca}^{2+}$ in the presence of $(\mathbf{H}) \mathrm{SPCA} 2 \mathrm{R}$ (control $n=30$ cells, SPCA2R $n=30$ cells) or (J) D379N (control $n=40$ cells, SPCA2R D379N $n=40$ cells). Student $t$ - test; ${ }^{* * *} p<0.001,{ }^{* *} p<0.01,{ }^{*} p<0.05,{ }^{\text {ns }} p>0.05$. 
A

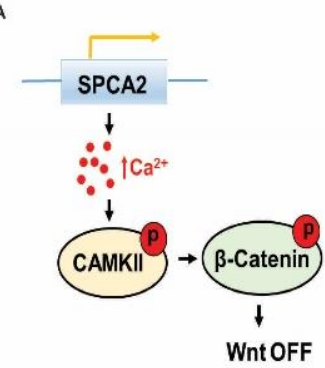

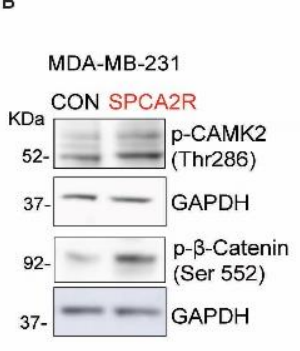

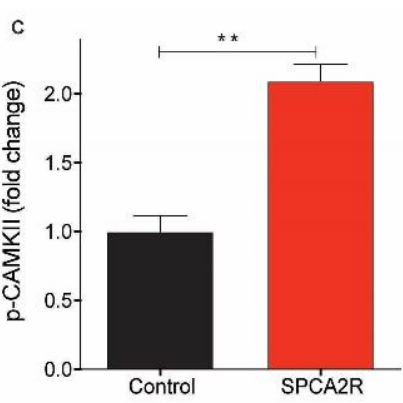

G
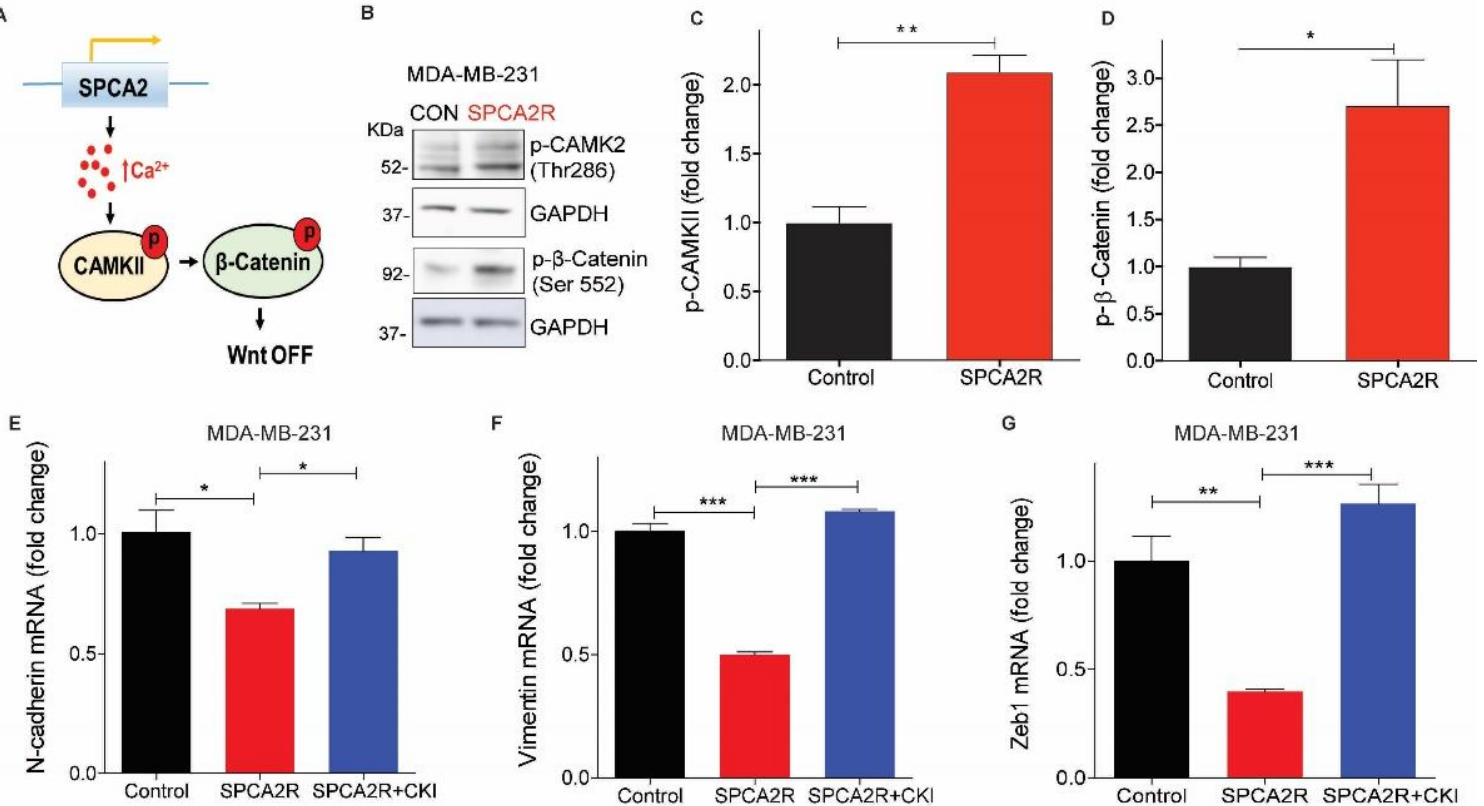

I
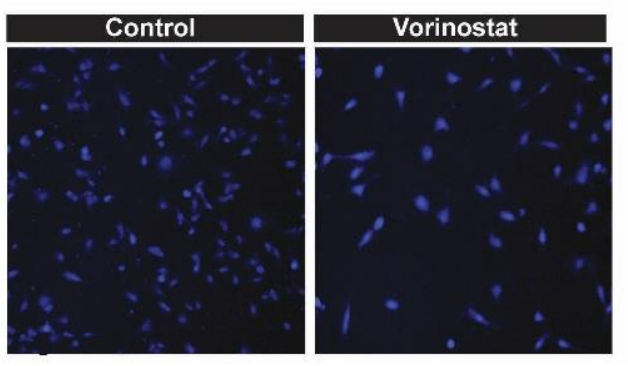

K

J MDA-MB-231
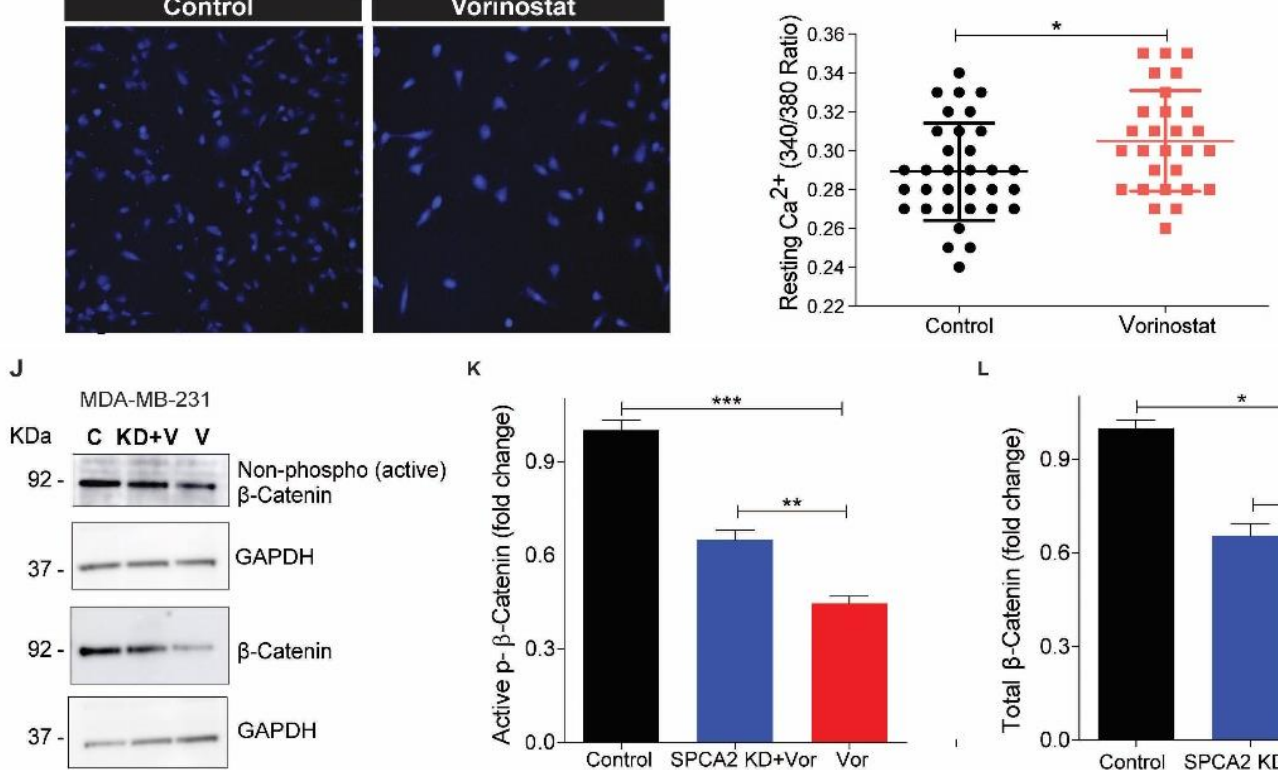

L

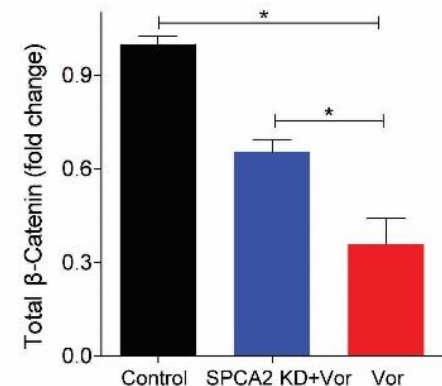

Figure 6. SPCA2 activates downstream Wnt $/ \mathrm{Ca}^{2+}$ signaling. (A) Schematic of downstream activation of Wnt $/ \mathrm{Ca}^{2+}$ signaling by SPCA2. Store-independent $\mathrm{Ca}^{2+}$ entry activated by SPCA2 increases cytoplasmic $\mathrm{Ca}^{2+}$, activating CAMKII and inactivating-catenin by phosphorylation, turning Wnt pathway OFF. (B) Representative Western blot of p-CAMKII and $\mathrm{p}-\beta$-catenin in MDA-MD-231 transfected with vector control or SPCA2R; GAPDH was used as a loading control. $(\mathbf{C}, \mathbf{D})$ Quantitation of Western blots $(n=3)$ by densitometry. (E-G) Ectopic expression of SPCA2 (SPCA2R) in MDA-MB231 decreased the mesenchymal gene markers, N-cadherin, vimentin, and Zeb1, which were significantly reversed by addition of CAM Kinase II inhibitor (KN 93 phosphate, $20 \mu \mathrm{M}, 24 \mathrm{~h}$ ). $n=3$. (H) Representative live cell $\mathrm{Ca}^{2+}$ imaging (2.5 $\times$ magnification) in calcium-free conditions using Fura2-AM in MDA-MB-231 treated with vehicle (control) or vorinostat $(2.5 \mu \mathrm{M}$ for $24 \mathrm{~h})$. (I) Fluorescence emission ratio of excitation at $340 / 380 \mathrm{~nm}$ showing increase in average resting $\mathrm{Ca}^{2+}$ in the presence of vorinostat ( $n=28$ cells) compared to vehicle control $(n=33$ cells). (J) Representative Western blot of non-phosphorylated (active) and total $\beta$-catenin in MDA-MD-231 control (scrambled shRNA) and SPCA2 KD, treated with vorinostat as indicated; GAPDH was used as a loading control. $(K, L)$ Quantitation of Western blots by densitometry $(n=3)$. SPCA2 KD significantly reversed the decrease in active and total levels of $\beta$-catenin by vorinostat. Student $t$-test, ${ }^{* * *} p<0.001,{ }^{* *} p<0.01,{ }^{*} p<0.05$. 
Next, we asked if HDACi-mediated increase in SPCA2 expression was sufficient to increase resting $\mathrm{Ca}^{2+}$ levels. We show that treatment of MDA-MB-231 with vorinostat $(2.5 \mu \mathrm{M})$ resulted in increased resting $\mathrm{Ca}^{2+}$ levels similar to ectopic SPCA2R expression (Figure $6 \mathrm{H}, \mathrm{I})$. Vorinostat decreased levels of active, non-phosphorylated $\beta$-catenin as well as total $\beta$-catenin levels (Figure $6 \mathrm{~J}-\mathrm{L}$ ), suggesting that Wnt signaling was turned OFF. However, knockdown of SPCA2 impaired the ability of vorinostat to decrease active and total $\beta$-catenin (Figure $6 \mathrm{~J}-\mathrm{L}$ ). Taken together, our results reveal an exciting new role for SPCA2 as an activator of $\mathrm{Wnt} / \mathrm{Ca}^{2+}$ signaling in TNBC.

\section{Discussion}

Histone modification by acetylation is enriched in transcriptionally active promoter and enhancer regions of the genome where it promotes decondensation of chromatin and facilitates access and recruitment of transcription factors [38]. HDAC inhibitors that enhance acetylation and gene transcription are currently being evaluated in various stages of clinical trials for TNBC/metastatic cancers (NCT02890069, NCT02708680, NCT04315233, and NCT04296942) (https:/ / clinicaltrials.gov). Although the FDA has approved the use of HDACi to treat some aggressive cancers, many patients eventually relapse after treatment. Furthermore, the efficacy of HDAC inhibitors in solid tumors is limited [39]. We have previously established a novel role for the secretory pathway $\mathrm{Ca}^{2+}$-ATPase SPCA2 as a tumor suppressor in highly metastatic TNBC cells [4]. In this study we demonstrate that TNBC tumors with low SPCA2 expression could benefit from HDACi treatment that transcriptionally elevates SPCA2 and restores deficient $\mathrm{Ca}^{2+}$ signaling to promote MET phenotypes in vitro. Differential methylation of CpG islands at the SPCA2 (ATP2C2) locus has been reported in several publications. Of note, treatment with resveratrol at 24 and $48 \mathrm{~h}$ resulted in hypomethylation of SPCA2 CpG islands in MDA-MB-231 cells [40]. This is consistent with our observation that resveratrol increases expression of SPCA2 (Figure S1F).

SPCA2 plays a role in regulating metastatic potential and cytotoxicity of HDAC inhibitors, highlighting the importance of calcium regulation in therapy. Risk stratification using biomarkers and signature genes was previously used to predict chemoresponse and prognosis in triple-negative breast cancer [41,42]. Thus, stratification of TNBC by SPCA2 expression could be useful in predicting the clinical efficacy of HDACi treatment. Previously, Varga et al. [11], showed that plasma membrane $\mathrm{Ca}^{2+}$-ATPase isoform PMCA4b is induced in response to HDACi in ER $\alpha+$ and HER2+ breast cancer cell lines such as MCF-7, but not in basal/triple negative breast cancer lines MDA-MB-231 and Hs578T where expression of this gene is already significantly elevated. In contrast, our study shows that SPCA2 expression in TNBC cell lines is low and can be increased by treatment with HDACi. Taken together, these two separate observations are consistent with our hypothesis that low basal $\mathrm{Ca}^{2+}$ in TNBC is necessary for maintaining the mesenchymal state. Here we show that elevating basal $\mathrm{Ca}^{2+}$ levels by increasing SPCA2-mediated store-independent $\mathrm{Ca}^{2+}$ entry is sufficient to reverse mesenchymal phenotypes. This is a mechanistically novel and significant function of calcium pumps in MET.

Frequent epigenetic inactivation of Wnt antagonist genes were reported in breast cancer which suggest that their loss of function contributes to activation of Wnt signaling in breast carcinogenesis [20]. For example, APCL, homologous to the adenomatous polyposis coli (APC) tumor suppressor gene, is known to regulate $\mathrm{Wnt} / \beta$-catenin pathway by promoting $\beta$-catenin ubiquitylation and degradation. HDAC inhibitors inhibited tumor growth and metastasis via upregulating APCL expression in breast cancer cells [43]. HDAC inhibitors reversed EMT by inhibiting Epithelial Cell Adhesion Molecule (EpCAM) cleavage and WNT signaling in breast cancer cells [12]. When combined with Wnt/ $\beta$-catenin pathway inhibitors, HDACi caused a dramatic decrease in cell viability by inducing the extrinsic apoptotic pathway in lung carcinoma cells [44]. In colon cancer cells, HDAC inhibitors were reported to induce cell cycle arrest and apoptosis by upregulating noncanonical Wnt signaling [45]. These results highlight that that HDAC inhibitors induce cell death and inhibit EMT through Wnt/ $\beta$-catenin pathway. 
The endoplasmic reticulum acts as a store of intracellular calcium that can be rapidly released into the cytoplasm to trigger a variety of cellular responses [46]. The $\mathrm{Wnt} / \mathrm{Ca}^{2+}$ pathway emerged with the finding that some Wnts and Fz receptors can stimulate intracellular $\mathrm{Ca}^{2+}$ release from ER, and this pathway is dependent on G-proteins [47,48]. Here, we identify a novel mechanism of activating Wnt $/ \mathrm{Ca}^{2+}$ signaling by extracellular $\mathrm{Ca}^{2+}$ and SPCA2-mediated store independent $\mathrm{Ca}^{2+}$ entry (SICE). The resulting elevation of cytoplasmic $\mathrm{Ca}^{2+}$ activates CAMK II signaling, leading to phosphorylation of $\beta$-catenin, which targets it for inactivation and degradation. We showed that SPCA2-mediated activation of the downstream components of $\mathrm{Wnt} / \mathrm{Ca}^{2+}$ signaling was necessary and sufficient to promote hallmarks of MET in TNBC cells. It is worth noting that this newly identified pathway may be Wnt ligand independent or there may be other ways to activate SICE that remain to be determined.

Our findings, summarized in the emerging model shown in Figure 7, provide novel mechanistic insights on druggable pathways that could be harnessed for treatment of metastatic cancers. We have previously shown that ectopic expression of SPCA2 in triplenegative breast cancer elevates baseline $\mathrm{Ca}^{2+}$ via SICE leading to phosphorylation and nuclear exclusion of YAP and suppression of EMT [4]. Multiple reports have shown YAP/ $\beta$ catenin signaling axis as key regulator in cancer progression in variety of cancers [49-53]. Therefore, SPCA2-YAP- $\beta$-catenin pathway warrants further investigation.

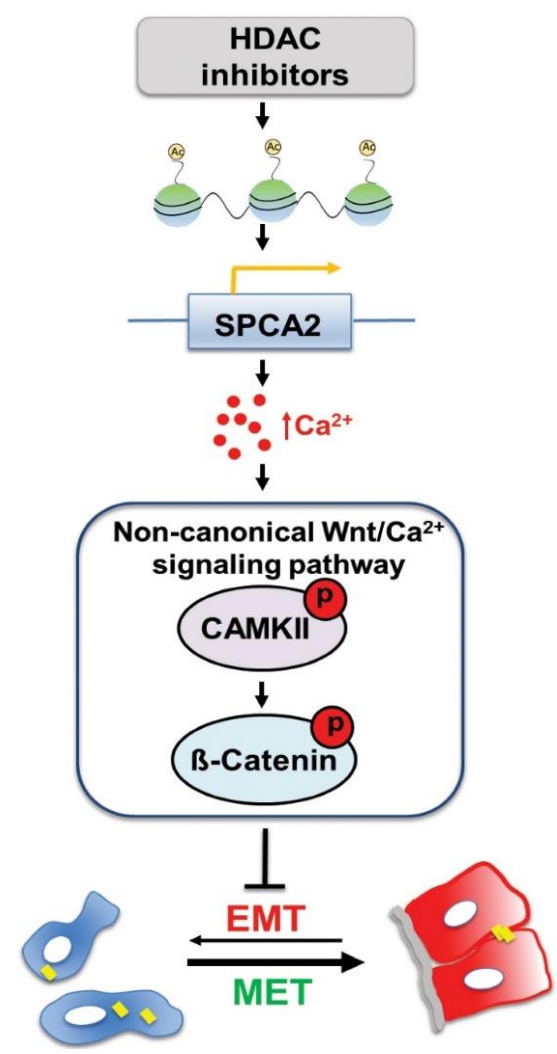

Figure 7. Epigenetic modulation of SPCA2 in TNBC reverses EMT through $\mathrm{Ca}^{2+} / \mathrm{Wnt}$ signaling. Breast cancer cells undergo reversible transitions between mesenchymal state, characterized by low cytosolic $\mathrm{Ca}^{2+}$ (blue) and detached junctional protein E-cadherin (yellow bars), and epithelial state, characterized by higher resting $\mathrm{Ca}^{2+}$ (red), attachment to the basement membrane (gray), and cell-cell junctions (yellow). Previous work showed that ectopic expression of SPCA2 in TNBC cells increases cytosolic $\mathrm{Ca}^{2+}$ and E-cadherin expression to promote epithelial phenotypes. In this study, we show that HDAC inhibitors (vorinostat and romidepsin) increase histone acetylation leading to increased SPCA2 transcription, which in turn elevates resting $\mathrm{Ca}^{2+}$ by activation of store-independent $\mathrm{Ca}^{2+}$ entry. $\mathrm{Ca}^{2+}$ activates non-canonical Wnt signaling by phosphorylating CAMKII and $\beta$-catenin, turning Wnt OFF. This blocks EMT and promotes MET. 


\section{Materials and Methods}

\subsection{Chemicals}

KN-93 phosphate (CAMK II inhibitor) was obtained from Tocris Bioscience (Bristol, UK), 5-Azacytidine from Selleck chemicals (Houston, TX, USA), and resveratrol from Sigma Aldrich (St. Louis, MO, USA).

\subsection{Media and Cells}

\subsubsection{Cell Culture}

Cells used in this study were MDA-MB-231 (ATCC HTB-26) and Hs578T (ATCC HTB-126). MDA-MB-231 and Hs578T cells were gown in DMEM (Thermo Fisher Scientific, Waltham, MA, USA) containing antibiotic, and 5-10\% FBS (Sigma-Aldrich). Cells were cultured with $5 \% \mathrm{CO}_{2}$ and at $37^{\circ} \mathrm{C}$ in a humidified incubator. All cell lines were grown for less than a month or no more than 6 passages. We did not see visible contamination by mycoplasma. Since SPCA2 expression is regulated by cell density, cells were maintained at $50-60 \%$ confluency in both knockdown experiments and controls. Although we used lentiviral transfection, resistant clones tended to appear after 2-3 passages, therefore all experiments used early passage cells.

\subsubsection{MTT Assay}

Cells were seeded at $\sim 3000$ cells/well in 96 well plates. After the cells were incubated overnight, they were treated with vorinostat for $80 \mathrm{~h}$. Thereafter, MTT dye (Thermo Fisher Scientific) was added to the cells for four hours, and SDS- $\mathrm{HCl}$ solution was added to each well and mixed thoroughly. After four hours of incubation, absorbance was measured at $570 \mathrm{~nm}$. Cell survival is calculated as the percentage normalized to control.

\subsection{HDAC Inhibitor Treatment}

Vorinostat (Vor) was obtained from cell signaling technology (Danvers, MA, USA) and romidepsin (Rom) from Selleck Chemicals. Stock solutions of vorinostat and romidepsin were prepared in DMSO. Cell lines were seeded into 6-well plates and incubated overnight, cells were treated with HDAC inhibitors when they reached 30 to $40 \%$ of confluency. For dose-dependent experiments, cells were treated with $2.5 \mu \mathrm{M}, 5 \mu \mathrm{M}$ and $10 \mu \mathrm{M}$ of vorinostat, and $5 \mathrm{nM}, 10 \mathrm{nM}$, and $15 \mathrm{nM}$ of romidepsin. To investigate changes in EMT markers, MDA-MB-231 and HS578T cells were treated $2.5 \mu \mathrm{M}$ of vorinostat and $5 \mathrm{nM}$ of romidepsin. Following $24 \mathrm{~h}$ of incubation, RNA was collected and qPCR was performed. Three replicate wells were tested per concentration.

\subsection{Epigenetic Modifications in ATP2C2 Promoter Region}

Epigenetic modifications in the promoter of SPCA2 were obtained from the UCSC Genome Browser Database (http:/ / genome.ucsc.edu/) and Eukaryotic Promoter Database (https:/ / epd.epfl.ch//index.php). Histone methylation and acetylation data was sourced from ENCODE through the IGV browser (https://igv.org/app/).

\subsection{Molecular Biology Techniques \\ 4.5.1. Lentiviral Transfection}

FUGW overexpression constructs, pLK0.1 shRNA lentiviral construction of SPCA2 was packaged and transfected according to previous methods [4], using pCMV- $\Delta 8.9$ and PMDG in HEK293T cells. Virus was collected after $24 \mathrm{~h}$ for 3 consecutive days and concentrated with Lenti-X Concentrator (Takara Bio USA, Mountain View, CA, USA). A mixture of two previously validated shRNA constructs for SPCA2 was used [29]. Cells were transfected with virus for $48 \mathrm{~h}$, and selected with puromycin $(1 \mu \mathrm{g} / \mathrm{mL}$ for MDA-MB-231). Since the basal SPCA2 expression is low in MDA-MB-231 cell line, the cells were transfected with knockdown virus 2-3 times to get a good efficiency. Knockdowns were confirmed by qPCR. Experiments were performed within 2-3 passages to ensure that knockdown was maintained. 


\subsection{2. cDNA Synthesis and Quantitative PCR}

One microgram of RNA was collected and used for cDNA synthesis (Applied Biosystems, Foster City, CA, USA). The qPCR mastermix was obtained from Thermo Fischer Scientific, $50 \mathrm{ng}$ of cDNA, and Taqman probe (Thermo Fischer Scientific) as specified; GAPDH (Hs02796624_g1), SPCA2 (Hs00939492_m1), SPCA1 (Hs00995930_m1), CDH1 (HS01023895_ m1), CDH2 (Hs00983056_m1), ZEB1 (Hs00232783_m1), SNAI2 (Hs00161904_m1), and Vimentin (Hs00958111_m1). GAPDH was used as an endogenous control.

\subsection{Western Blotting}

Cells were collected, and lysed in RIPA buffer (Thermo Fisher Scientific) supplemented with protease inhibitor cocktail, and phosphatase inhibitors. Protein quantification was done by the bicinchoninic acid assay. Thirty $\mu \mathrm{g}$ of protein in each sample was resolved by electrophoresis using $4-12 \%$ bis-tris gels (Thermo Fisher Scientific) and transferred to nitrocellulose membrane (Bio-Rad, Hercules, CA, USA). Immunoblots were probed with antibodies (1:1000) from Cell Signaling Technologies, followed by incubation with HRP-conjugated secondary antibodies. Proteins were visualized using chemiluminescence substrate. Blots were analyzed using ImageJ. Antibodies used in this study and corresponding catalog numbers are as follows: Acetyl-Histone H3 (9677), GAPDH $(97,166)$, Vimentin (5741), Phospho-CaMKII (12,716), Phospho- $\beta$-Catenin (9566), Non-phospho (Active) $\beta$-Catenin (8814), and $\beta$-Catenin (8480). Uncropped western blots were included in Figures S5 and S6.

\subsection{Imaging}

4.7.1. Immunofluorescence

Cells were cultured on glass coverslips and were rinsed with PBS and pre-extracted with $1 \times$ PHEM buffer, $8 \%$ sucrose, and $0.025 \%$ saponin. Cells were fixed with $4 \%$ paraformaldehyde for $30 \mathrm{~min}$ and were rinsed and washed with PBS 3 times for $5 \mathrm{~min}$ each. After blocking in $1 \%$ BSA, cells were incubated with overnight in $4{ }^{\circ} \mathrm{C}$ using vimentin antibody (Cell Signaling Technologies). Cells were rinsed with $0.2 \%$ BSA 3 times for $5 \mathrm{~min}$ and were then incubated with a fluorescent secondary antibody in 1\% BSA and $0.025 \%$ saponin buffer for $30 \mathrm{~min}$ at room temperature. Coverslips were washed and mounted onto slides with mounting media (Agilent, Santa Clara, CA, USA). Immunofluorescent staining was analyzed using ImageJ.

\subsubsection{Live Cell Calcium Imaging}

Live imaging of $\mathrm{Ca}^{2+}$ was performed using Fura2-AM (Invitrogen, Carlsbad, CA, USA). MDA-MB-231 cells were transfected with vector (Control) or SPCA2R or SPCA2R D379N were treated with vorinostat for $24 \mathrm{~h}$, washed and treated with Fura2-AM in imaging buffer $(20 \mathrm{mM}$ Hepes, $126 \mathrm{mM}, \mathrm{NaCl}, 4.5 \mathrm{mM} \mathrm{KCl}, 2 \mathrm{mM} \mathrm{MgCl} 2,10 \mathrm{mM}$ glucose at pH 7.4) for $30 \mathrm{~min}$. Cells were excited at $340 \mathrm{~nm}$ and $380 \mathrm{~nm}$, and Fura emission was captured at $505 \mathrm{~nm}[4]$.

\subsection{Boyden Chamber Assay}

MDA-MB-231 cells were maintained in DMEM media without FBS for $4 \mathrm{~h}$. Approximately $5 \times 10^{4}$ cells of each condition were plated in $100 \mu \mathrm{L}$ DMEM media without FBS in $6.5 \mathrm{~mm}$ Transwell chambers with $8.0 \mathrm{~mm}$ Pore Polyester Membrane Insert (Corning Inc., Corning, NY, USA), and transferred to a 24 -well dish containing $500 \mu \mathrm{L}$ fresh media $(0.5 \%$ FBS containing DMEM) with/without vorinostat. After $24 \mathrm{~h}$, cells were fixed with $4 \%$ paraformaldehyde for $30 \mathrm{~min}$, then $0.5 \%$ crystal violet (Sigma-Aldrich) was added for $1 \mathrm{~h}$, and washed with PBS. Using a microscope (Nikon, Eclipse TS100), photos of membrane insert were captured at $10 \times$ test. ImageJ software was used to quantify migration. 


\section{Conclusions}

Ionized $\mathrm{Ca}^{2+}$ is a versatile, essential, and ubiquitous second messenger that impacts all aspects of cell fate and function, including key hallmarks of cancer such as proliferation, differentiation, migration, invasion, and apoptosis. With the advent of pharmacogenomics and molecular profiling, tailored tumor treatment is now possible with a potential for new and improved therapies aimed at $\mathrm{Ca}^{2+}$ signaling pathways and genes. Armed with a recent mechanistic understanding of the subtype-specific role of SPCA2 in $\mathrm{Ca}^{2+}$ signaling [18], we explored innovative therapeutic regimens for metastatic breast cancer. We showed that FDA-approved HDACi, vorinostat, and romidepsin, were effective in increasing SPCA2 levels at clinically relevant concentrations and that SPCA2 induction was necessary for reversal of EMT phenotypes through downstream $\mathrm{Wnt} / \mathrm{Ca}^{2+}$ signaling. Although we focused on HDAC inhibitors in this study, we show that other classes of epigenetic modulators, such as DNA methyltransferase inhibitors, could also be effective in upregulating SPCA2, making us optimistic that this approach will be broadly useful. Alternatively, drugs that bypass the role of SPCA2 to directly activate $\mathrm{Ca}^{2+}$ channels could also restore basal $\mathrm{Ca}^{2+}$ signaling and reverse EMT in TNBC cells. Our findings provide incentive for screening of new or repurposed drugs that exploit subtype-selective $\mathrm{Ca}^{2+}$ signaling pathways to reverse EMT in breast tumors.

Supplementary Materials: The following are available online at https:/ / www.mdpi.com/2072-6694/ 13/2/259/s1, Figure S1: Epigenetic modification in SPCA promoter region, Figure S2: HDAC inhibitors promote MET phenotype TNBC cells, Figure S3: SPCA2 KD induced EMT changes in TNBC cell lines, Figure S4: Extracellular $\mathrm{Ca}^{2+}$ entry activates non-canonical Wnt/ $\mathrm{Ca}^{2+}$ pathway; Figure S5: Uncropped western blots for Figures 2, 3 and 5; Figure S6: Uncropped western blots for Figure 6.

Author Contributions: Conceptualization, M.R.M. and R.R.; methodology, M.R.M., M.K., D.K.D. and R.R.; software, M.R.M. and R.R.; validation, M.R.M., M.K., D.K.D. and R.R.; formal analysis, M.R.M., M.K., D.K.D. and R.R.; investigation, M.R.M., M.K., D.K.D. and R.R.; resources, R.R.; data curation, M.R.M., M.K., D.K.D. and R.R.; writing and editing, M.R.M. and R.R.; visualization, M.R.M. and R.R.; supervision, R.R.; project administration, R.R.; funding acquisition, M.R.M. and R.R. All authors have read and agreed to the published version of the manuscript.

Funding: R.R. was supported by grants from the NIH (R01DK108304) and BSF (13044). M.R.M is the recipient of AACR-AstraZeneca Breast Cancer Research Fellowship. M.K. was a recipient of Ruth L. Kirschstein Individual National Research Service Award F31CA220967.

Institutional Review Board Statement: Not applicable.

Informed Consent Statement: Not applicable.

Data Availability Statement: Raw western blots are uploaded in the supplementary materials. Other raw data that support the findings of this study are available on request from the corresponding author (R.R).

Acknowledgments: M.R.M. acknowledges the support of American Association of Cancer Research (AACR). M.J.K acknowledges the support of the graduate training programs in Cellular \& Molecular Medicine, at the Johns Hopkins University. Authors like to thank Vijender Singh, Computational Biology Core, University of Connecticut, for his suggestions regarding epigenetic modification of promoter region.

Conflicts of Interest: The authors declare no conflict of interest. The funders had no role in the design of the study; in the collection, analyses, or interpretation of data; in the writing of the manuscript, or in the decision to publish the results.

\section{References}

1. Yao, H.; He, G.; Yan, S.; Chen, C.; Song, L.; Rosol, T.J.; Deng, X. Triple-negative breast cancer: Is there a treatment on the horizon? Oncotarget 2017, 8, 1913. [CrossRef] [PubMed]

2. Siddharth, S.; Sharma, D. Racial Disparity and Triple-Negative Breast Cancer in African-American Women: A Multifaceted Affair between Obesity, Biology, and Socioeconomic Determinants. Cancers 2018, 10, 514. [CrossRef] [PubMed]

3. Anders, C.; Carey, L.A. Understanding and treating triple-negative breast cancer. Oncol. (Williston Park) 2008, 22, 1233-1239, discussion 1239-1240, 1243. 
4. Dang, D.K.; Makena, M.R.; Llongueras, J.P.; Prasad, H.; Ko, M.; Bandral, M.; Rao, R. A Ca ${ }^{2+}$-ATPase Regulates E-cadherin Biogenesis and Epithelial-Mesenchymal Transition in Breast Cancer Cells. Mol. Cancer Res. 2019, 17, 1735-1747. [CrossRef]

5. Sanchez-Tillo, E.; Liu, Y.; de Barrios, O.; Siles, L.; Fanlo, L.; Cuatrecasas, M.; Darling, D.S.; Dean, D.C.; Castells, A.; Postigo, A. EMT-activating transcription factors in cancer: Beyond EMT and tumor invasiveness. Cell. Mol. Life Sci. CMLS 2012, 69, 3429-3456. [CrossRef]

6. Gatla, H.R.; Muniraj, N.; Thevkar, P.; Yavvari, S.; Sukhavasi, S.; Makena, M.R. Regulation of Chemokines and Cytokines by Histone Deacetylases and an Update on Histone Decetylase Inhibitors in Human Diseases. Int. J. Mol. Sci. 2019, $20,1110$. [CrossRef]

7. Garmpis, N.; Damaskos, C.; Garmpi, A.; Kalampokas, E.; Kalampokas, T.; Spartalis, E.; Daskalopoulou, A.; Valsami, S.; Kontos, M.; Nonni, A.; et al. Histone Deacetylases as New Therapeutic Targets in Triple-negative Breast Cancer: Progress and Promises. Cancer Genom. Proteom. 2017, 14, 299-313. [CrossRef]

8. Fedele, P.; Orlando, L.; Cinieri, S. Targeting triple negative breast cancer with histone deacetylase inhibitors. Expert Opin. Investig. Drugs 2017, 26, 1199-1206. [CrossRef]

9. Makena, M.R.; Koneru, B.; Nguyen, T.H.; Kang, M.H.; Reynolds, C.P. Reactive Oxygen Species-Mediated Synergism of Fenretinide and Romidepsin in Preclinical Models of T-cell Lymphoid Malignancies. Mol. Cancer Ther. 2017, 16, 649-661. [CrossRef]

10. Raynal, N.J.-M.; Lee, J.T.; Wang, Y.; Beaudry, A.; Madireddi, P.; Garriga, J.; Malouf, G.G.; Dumont, S.; Dettman, E.J.; Gharibyan, V. Targeting calcium signaling induces epigenetic reactivation of tumor suppressor genes in cancer. Cancer Res. 2016, 76, 1494-1505. [CrossRef]

11. Varga, K.; Hollósi, A.; Pászty, K.; Hegedûs, L.; Szakács, G.; Tímár, J.; Papp, B.; Enyedi, Á.; Padányi, R. Expression of calcium pumps is differentially regulated by histone deacetylase inhibitors and estrogen receptor alpha in breast cancer cells. BMC Cancer 2018, 18, 1029. [CrossRef] [PubMed]

12. Su, Y.; Hopfinger, N.R.; Nguyen, T.D.; Pogash, T.J.; Santucci-Pereira, J.; Russo, J. Epigenetic reprogramming of epithelial mesenchymal transition in triple negative breast cancer cells with DNA methyltransferase and histone deacetylase inhibitors. $J$. Exp. Clin. Cancer Res. 2018, 37, 314. [CrossRef] [PubMed]

13. Shah, P.; Gau, Y.; Sabnis, G. Histone deacetylase inhibitor entinostat reverses epithelial to mesenchymal transition of breast cancer cells by reversing the repression of E-cadherin. Breast Cancer Res. Treat. 2014, 143, 99-111. [CrossRef] [PubMed]

14. Schech, A.; Kazi, A.; Yu, S.; Shah, P.; Sabnis, G. Histone deacetylase inhibitor entinostat inhibits tumor-initiating cells in triple-negative breast cancer cells. Mol. Cancer Ther. 2015, 14, 1848-1857. [CrossRef]

15. Tate, C.R.; Rhodes, L.V.; Segar, H.C.; Driver, J.L.; Pounder, F.N.; Burow, M.E.; Collins-Burow, B.M. Targeting triple-negative breast cancer cells with the histone deacetylase inhibitor panobinostat. Breast Cancer Res. 2012, 14, R79. [CrossRef]

16. Rhodes, L.V.; Tate, C.R.; Segar, H.C.; Burks, H.E.; Phamduy, T.B.; Hoang, V.; Elliott, S.; Gilliam, D.; Pounder, F.N.; Anbalagan, M. Suppression of triple-negative breast cancer metastasis by pan-DAC inhibitor panobinostat via inhibition of ZEB family of EMT master regulators. Breast Cancer Res. Treat. 2014, 145, 593-604. [CrossRef]

17. Dang, D.; Rao, R. Calcium-ATPases: Gene disorders and dysregulation in cancer. Biochim. Biophys. Acta (BBA)-Mol. Cell Res. 2016, 1863, 1344-1350. [CrossRef]

18. Makena, M.R.; Rao, R. Subtype Specific Targeting of Calcium Signaling in Breast Cancer. Cell Calcium 2019, 85, 102109. [CrossRef]

19. Ram Makena, M.; Gatla, H.; Verlekar, D.; Sukhavasi, S.; KPandey, M.; CPramanik, K. Wnt/ $\beta$-catenin signaling: The culprit in pancreatic carcinogenesis and therapeutic resistance. Int. J. Mol. Sci. 2019, 20, 4242. [CrossRef]

20. Suzuki, H.; Toyota, M.; Caraway, H.; Gabrielson, E.; Ohmura, T.; Fujikane, T.; Nishikawa, N.; Sogabe, Y.; Nojima, M.; Sonoda, T. Frequent epigenetic inactivation of Wnt antagonist genes in breast cancer. Br. J. Cancer 2008, 98, 1147-1156. [CrossRef]

21. Flentke, G.R.; Garic, A.; Hernandez, M.; Smith, S.M. CaMKII represses transcriptionally active $\beta$-catenin to mediate acute ethanol neurodegeneration and can phosphorylate $\beta$-catenin. J. Neurochem. 2014, 128, 523-535. [CrossRef] [PubMed]

22. Park, H.-B.; Kim, J.-W.; Baek, K.-H. Regulation of Wnt Signaling through Ubiquitination and Deubiquitination in Cancers. Int. J. Mol. Sci. 2020, 21, 3904. [CrossRef] [PubMed]

23. Tian, X.; Liu, Z.; Niu, B.; Zhang, J.; Tan, T.K.; Lee, S.R.; Zhao, Y.; Harris, D.C.; Zheng, G. E-cadherin/ $\beta$-catenin complex and the epithelial barrier. J. Biomed. Biotechnol. 2011, 2011, 567305. [CrossRef] [PubMed]

24. Chang, Y.-W.; Su, Y.-J.; Hsiao, M.; Wei, K.-C.; Lin, W.-H.; Liang, C.-J.; Chen, S.-C.; Lee, J.-L. Diverse targets of $\beta$-catenin during the epithelial-mesenchymal transition define cancer stem cells and predict disease relapse. Cancer Res. 2015, 75, 3398-3410. [CrossRef]

25. Chiu, H.W.; Yeh, Y.L.; Wang, Y.C.; Huang, W.J.; Chen, Y.A.; Chiou, Y.S.; Ho, S.Y.; Lin, P.; Wang, Y.J. Suberoylanilide hydroxamic acid, an inhibitor of histone deacetylase, enhances radiosensitivity and suppresses lung metastasis in breast cancer in vitro and in vivo. PLoS ONE 2013, 8, e76340. [CrossRef]

26. Srivastava, R.K.; Kurzrock, R.; Shankar, S. MS-275 sensitizes TRAIL-resistant breast cancer cells, inhibits angiogenesis and metastasis, and reverses epithelial-mesenchymal transition in vivo. Mol. Cancer Ther. 2010, 9, 3254-3266. [CrossRef]

27. Munster, P.N.; Thurn, K.T.; Thomas, S.; Raha, P.; Lacevic, M.; Miller, A.; Melisko, M.; Ismail-Khan, R.; Rugo, H.; Moasser, M.; et al. A phase II study of the histone deacetylase inhibitor vorinostat combined with tamoxifen for the treatment of patients with hormone therapy-resistant breast cancer. Br. J. Cancer 2011, 104, 1828-1835. [CrossRef] 
28. Tu, Y.; Hershman, D.L.; Bhalla, K.; Fiskus, W.; Pellegrino, C.M.; Andreopoulou, E.; Makower, D.; Kalinsky, K.; Fehn, K.; Fineberg, S.; et al. A phase I-II study of the histone deacetylase inhibitor vorinostat plus sequential weekly paclitaxel and doxorubicin-cyclophosphamide in locally advanced breast cancer. Breast Cancer Res. Treat. 2014, 146, 145-152. [CrossRef]

29. Feng, M.; Grice, D.M.; Faddy, H.M.; Nguyen, N.; Leitch, S.; Wang, Y.; Muend, S.; Kenny, P.A.; Sukumar, S.; Roberts-Thomson, S.J. Store-independent activation of Orai1 by SPCA2 in mammary tumors. Cell 2010, 143, 84-98. [CrossRef]

30. Makena, M.R.; Nguyen, T.H.; Koneru, B.; Hindle, A.; Chen, W.-H.; Verlekar, D.U.; Kang, M.H.; Reynolds, C.P. Vorinostat and fenretinide synergize in preclinical models of T-cell lymphoid malignancies. Anti-Cancer Drugs 2020, 32, 34-43. [CrossRef]

31. Thompson, E.W.; Paik, S.; Brunner, N.; Sommers, C.L.; Zugmaier, G.; Clarke, R.; Shima, T.B.; Torri, J.; Donahue, S.; Lippman, M.E.; et al. Association of increased basement membrane invasiveness with absence of estrogen receptor and expression of vimentin in human breast cancer cell lines. J. Cell Physiol. 1992, 150, 534-544. [CrossRef] [PubMed]

32. Wawruszak, A.; Kalafut, J.; Okon, E.; Czapinski, J.; Halasa, M.; Przybyszewska, A.; Miziak, P.; Okla, K.; Rivero-Muller, A.; Stepulak, A. Histone deacetylase inhibitors and phenotypical transformation of cancer cells. Cancers 2019, 11, 148. [CrossRef] [PubMed]

33. Suraweera, A.; O'Byrne, K.J.; Richard, D.J. Combination therapy with histone deacetylase inhibitors (HDACi) for the treatment of cancer: Achieving the full therapeutic potential of HDACi. Front. Oncol. 2018, 8, 92. [CrossRef] [PubMed]

34. Makena, M.R.; Ko, M.; Mekile, A.X.; Dang, D.K.; Warrington, J.M.; Buckhaults, P.J.; Talbot, C.; Rao, R. Store Independent Ca2+ Entry Regulates the DNA Damage Response in Breast Cancer Cells. bioRxiv 2020. [CrossRef]

35. Cantonero, C.; Sanchez-Collado, J.; Gonzalez-Nunez, M.A.; Salido, G.M.; Lopez, J.J.; Jardin, I.; Rosado, J.A. Store-independent Orai1-mediated $\mathrm{Ca}(2+)$ entry and cancer. Cell Calcium 2019, 80, 1-7. [CrossRef]

36. Pohl, S.-G.; Brook, N.; Agostino, M.; Arfuso, F.; Kumar, A.P.; Dharmarajan, A. Wnt signaling in triple-negative breast cancer. Oncogenesis 2017, 6, e310. [CrossRef]

37. Verheyen, E.M.; Gottardi, C.J. Regulation of Wnt/ $\beta$-catenin signaling by protein kinases. Dev. Dyn. Off. Publ. Am. Assoc. Anat. 2010, 239, 34-44. [CrossRef]

38. Bannister, A.J.; Kouzarides, T. Regulation of chromatin by histone modifications. Cell Res. 2011, 21, 381-395. [CrossRef]

39. Ferrarelli, L.K. HDAC inhibitors in solid tumors and blood cancers. Sci. Signal. 2016, 9, ec216. [CrossRef]

40. Medina-Aguilar, R.; Pérez-Plasencia, C.; Gariglio, P.; Marchat, L.A.; Flores-Pérez, A.; López-Camarillo, C.; Mena, J.G. DNA methylation data for identification of epigenetic targets of resveratrol in triple negative breast cancer cells. Data Brief 2017, 11, 169-182. [CrossRef]

41. Yue, Y.; Astvatsaturyan, K.; Cui, X.; Zhang, X.; Fraass, B.; Bose, S. Stratification of prognosis of triple-negative breast cancer patients using combinatorial biomarkers. PLoS ONE 2016, 11, e0149661. [CrossRef] [PubMed]

42. Kim, E.-K.; Park, A.K.; Ko, E.; Park, W.-Y.; Lee, K.-M.; Noh, D.-Y.; Han, W. Risk stratification of triple-negative breast cancer with core gene signatures associated with chemoresponse and prognosis. Breast Cancer Res. Treat. 2019, 178, 185-197. [CrossRef] [PubMed]

43. Qin, G.; Li, Y.; Xu, X.; Wang, X.; Zhang, K.; Tang, Y.; Qiu, H.; Shi, D.; Zhang, C.; Long, Q. Panobinostat (LBH589) inhibits Wnt/ $\beta$-catenin signaling pathway via upregulating APCL expression in breast cancer. Cell. Signal. 2019, 59, 62-75. [CrossRef] [PubMed]

44. Akgun, O.; Erkisa, M.; Ari, F. Effective and new potent drug combination: Histone deacetylase and Wnt/ $\beta$-catenin pathway inhibitors in lung carcinoma cells. J. Cell. Biochem. 2019, 120, 15467-15482. [CrossRef] [PubMed]

45. Sikandar, S.; Dizon, D.; Shen, X.; Li, Z.; Besterman, J.; Lipkin, S.M. The class I HDAC inhibitor MGCD0103 induces cell cycle arrest and apoptosis in colon cancer initiating cells by upregulating Dickkopf-1 and non-canonical Wnt signaling. Oncotarget 2010, 1, 596. [CrossRef]

46. Suisse, A.; Treisman, J.E. Reduced SERCA function preferentially affects Wnt signaling by retaining E-cadherin in the endoplasmic reticulum. Cell Rep. 2019, 26, 322-329. [CrossRef]

47. Komiya, Y.; Habas, R. Wnt signal transduction pathways. Organogenesis 2008, 4, 68-75. [CrossRef]

48. Kuhl, M.; Sheldahl, L.C.; Park, M.; Miller, J.R.; Moon, R.T. The Wnt/Ca ${ }^{2+}$ pathway: A new vertebrate Wnt signaling pathway takes shape. Trends Genet. 2000, 16, 279-283. [CrossRef]

49. Liu, T.; Zhou, L.; Yang, K.; Iwasawa, K.; Kadekaro, A.L.; Takebe, T.; Andl, T.; Zhang, Y. The $\beta$-catenin/YAP signaling axis is a key regulator of melanoma-associated fibroblasts. Signal Transduct. Target. Ther. 2019, 4, 1-15. [CrossRef]

50. Deng, F.; Peng, L.; Li, Z.; Tan, G.; Liang, E.; Chen, S.; Zhao, X.; Zhi, F. YAP triggers the Wnt/ $\beta$-catenin signalling pathway and promotes enterocyte self-renewal, regeneration and tumorigenesis after DSS-induced injury. Cell Death Dis. 2018, 9, 1-16. [CrossRef]

51. Park, H.W.; Kim, Y.C.; Yu, B.; Moroishi, T.; Mo, J.-S.; Plouffe, S.W.; Meng, Z.; Lin, K.C.; Yu, F.-X.; Alexander, C.M. Alternative Wnt signaling activates YAP/TAZ. Cell 2015, 162, 780-794. [CrossRef] [PubMed]

52. Wang, Y.; Pan, P.; Wang, Z.; Zhang, Y.; Xie, P.; Geng, D.; Jiang, Y.; Yu, R.; Zhou, X. $\beta$-catenin-mediated YAP signaling promotes human glioma growth. J. Exp. Clin. Cancer Res. 2017, 36, 1-11. [CrossRef] [PubMed]

53. Rosenbluh, J.; Nijhawan, D.; Cox, A.G.; Li, X.; Neal, J.T.; Schafer, E.J.; Zack, T.I.; Wang, X.; Tsherniak, A.; Schinzel, A.C. $\beta$-Catenindriven cancers require a YAP1 transcriptional complex for survival and tumorigenesis. Cell 2012, 151, 1457-1473. [CrossRef] [PubMed] 